\title{
A synthetic protein as efficient multitarget regulator against complement over-activation
}

Natalia Ruiz-Molina ${ }^{1}$, Juliana Parsons ${ }^{1}$, Madeleine Müller ${ }^{1}$, Sebastian N.W Hoernstein ${ }^{1}$, Lennard L. Bohlender ${ }^{1}$, Steffen Pumple ${ }^{1}$, Peter F. Zipfel ${ }^{2,3}$, Karsten Häffner ${ }^{4}$ Ralf Reski $^{1,5}$, Eva L. Decker ${ }^{1 \star}$

${ }^{1}$ Plant Biotechnology, Faculty of Biology, University of Freiburg, Freiburg, Germany.

${ }^{2}$ Department of Infection Biology, Leibniz Institute for Natural Product Research and Infection Biology, Jena, Germany.

${ }^{3}$ Institute of Microbiology, Friedrich Schiller University, Jena, Germany.

${ }^{4}$ Faculty of Medicine, Department of Internal Medicine IV, Medical Center - University Freiburg, University of Freiburg, Freiburg, Germany.

${ }^{5}$ Signalling Research Centres BIOSS and CIBSS, University of Freiburg, Freiburg, Germany.

*Correspondence: Eva L. Decker, eva.decker@biologie.uni-freiburg.de

†ORCID: 0000-0002-0170-6000 (NRM), 0000-0001-6261-2342 (JP), orcid.org/0000-0002-45997807 (LLB), 0000-0002-2095-689X (SNWH), 0000-0002-6149-2411(PFZ), 0000-0002-5496-6711 (RR), 0000-0002-9151-1361 (ELD)

Author contributions: NRM performed most of the experiments, MM performed some of the binding tests, SP improved the purification process of the moss-made regulators, SNWH and LLB performed the MS data analysis, NRM, JP, RR and ELD designed the study and wrote the manuscript. PFZ and KH discussed data and provided comments on the manuscript.

Competing interest Statement: The authors are inventors of patents and patent applications related to the production of recombinant proteins in moss. $R R$ is an inventor of the moss bioreactor and a founder of Greenovation Biotech, now eleva $\mathrm{GmbH}$. He currently serves as advisory board member of this company.

Keywords: Physcomitrella, complement factor $\mathrm{H}$, plant-based biopharmaceuticals, complementassociated diseases, moss bioreactor. 


\begin{abstract}
The complement system constitutes the innate defense against pathogens. Its dysregulation leads to diseases and is a critical determinant in many viral infections, e.g.COVID-19. Factor $\mathrm{H}(\mathrm{FH})$ is the main regulator of the alternative pathway of complement activation and could be a therapy to restore homeostasis. However, recombinant $\mathrm{FH}$ is not available. Engineered $\mathrm{FH}$ versions may present alternative therapeutics. Here, we designed a synthetic protein, MFHR13, as a multitarget complement regulator. It combines the dimerization and C5-regulatory domains of human $\mathrm{FH}$ related protein 1 (FHR1) with the C3-regulatory and cell surface recognition domains of human $\mathrm{FH}$. MFHR13 includes the FH variant I62, which we characterized to induce improved C3b binding and cofactor activity compared to the variant V62. After comparative protein structure modelling, we introduced the SCR $\mathrm{FH}_{13}$, which includes an $\mathrm{N}$-glycosylation site for higher protein stability. In summary, the fusion protein MFHR13 comprises SCRs FHR1 1-2: $\mathrm{FH}_{1-4}: \mathrm{FH}_{13}: \mathrm{FH}_{19-20}$. It shows an enhanced heparin binding and protects sheep erythrocytes from complement attack exhibiting 26 and 4-fold the regulatory activity of eculizumab and human $\mathrm{FH}$, respectively. Furthermore, it also blocks the terminal pathway of complement activation and we demonstrate that MFHR13 and FHR1 bind to all proteins forming the membrane attack complex, which contributes to the mechanistic understanding of FHR1. We consider MFHR13 a promising candidate as a therapeutic for complement-associated diseases.
\end{abstract}




\section{Introduction}

The complement is a fundamental part of the human immune system and constitutes the innate defense against infection agents. It consists of approximately 50 plasma and membrane-bound proteins forming a surveillance network, whose core function is the recognition and destruction of microbial invaders (1). Complement activation can occur by the classical (CP), lectin (LP) or alternative (AP) pathways, which converge at complement component $\mathrm{C} 3$ activation and end up in membrane attack complex (MAC) formation, triggering lysis of invading pathogens and inflammation (2).

The AP contributes to up to $80 \%$ of the overall complement activation (3) and is spontaneously activated by hydrolysis of $\mathrm{C} 3$ to $\mathrm{C} 3\left(\mathrm{H}_{2} \mathrm{O}\right)$, with $\mathrm{C} 3 \mathrm{~b}$-like activity. $\mathrm{C} 3\left(\mathrm{H}_{2} \mathrm{O}\right)$, together with the factor $\mathrm{B}$ (FB) fragment $\mathrm{Bb}$, builds the initial $\mathrm{C} 3$ convertase $\left(\mathrm{C} 3\left(\mathrm{H}_{2} \mathrm{O}\right) \mathrm{Bb}\right)$ in fluid phase, which cleaves $\mathrm{C} 3$ to $\mathrm{C} 3 \mathrm{a}$ and $\mathrm{C} 3 \mathrm{~b}$. C3b mediates surface opsonization and amplifies complement activation, by building further $\mathrm{C} 3$ convertases $(\mathrm{C} 3 \mathrm{bBb})$ together with $\mathrm{FB}$ and FD. In addition the AP acts as an amplification mechanism, even when complement was activated by the CP or LP (4). As a consequence of excess C3b, C5 is activated, either by cleavage into C5a and C5b, or without proteolytic cleavage at very high densities of $\mathrm{C} 3 \mathrm{~b}$ on target surfaces, leading to C5b-like activated C5 (5). While C5b or C5b-like activated C5 bind to C6, C7, C8 and C9 leading to MAC formation (also called terminal complement complex - TCC) and cell destruction, C3a and C5a are anaphylatoxins that trigger cell recruitment and inflammation (6) (Fig. 1a).

As complement activation can also damage intact body cells, the activation of the system is tightly controlled, especially by factor $\mathrm{H}(\mathrm{FH})$. $\mathrm{FH}$ is a $155 \mathrm{kDa}$ glycoprotein, consisting of 20 globular domains, the short consensus repeats (SCR). The SCRs 1-4 (further named $\mathrm{FH}_{1-4}$ ) act as a cofactor for factor I-mediated proteolytic degradation of $\mathrm{C} 3 \mathrm{~b}$ to inactive $\mathrm{iC} 3 \mathrm{~b}$ (which is subsequently degraded to $\mathrm{C} 3 \mathrm{c}$ and $\mathrm{C} 3 \mathrm{dg}$ and finally the latter to $\mathrm{C} 3 \mathrm{~d}$ ), and accelerate the dissociation of C3 convertases in serum and on host cell surfaces $(7,8)$. FH binds to sialic acids and glycosaminoglycans on healthy host cells, protecting them from complement attack. The cellsurface binding domains are mainly located on SCRs $\mathrm{FH}_{7}$ and $\mathrm{FH}_{20}$, while the contribution of $\mathrm{FH}_{13}$ is still discussed (9). $\mathrm{FH}$ binds also through $\mathrm{FH}_{19-20}$ to $\mathrm{C} 3 \mathrm{~d}$, which contains the $\mathrm{C} 3 \mathrm{~b}$-thioester domain (TED) that attaches to cell surfaces $(10,11)$.

Five factor $\mathrm{H}$-related proteins (FHRs) fine-tune $\mathrm{FH}$-regulatory activity. The C-terminal region of $\mathrm{FH}$ $\left(\mathrm{FH}_{19-20}\right)$ is highly conserved in all $\mathrm{FHRs}$, while none of them contains regions homologous to $\mathrm{FH}_{1-4}$ (8). Of particular interest is FHR1, a regulator of C5 activation, which inhibits the last steps of the complement cascade (terminal pathway) and the MAC formation $(10,12)$.

Mutations in FH, FHRs or other complement-related genes are associated with diseases such as age-related macular degeneration (AMD), atypical hemolytic uremic syndrome (aHUS), C3 glomerulopathies (C3G), and paroxysmal nocturnal hemoglobinuria (PNH) (8, 13). However, protective haplotypes have also been identified; one of them is the polymorphism $\mathrm{FH}^{\mathrm{V} 621}$ (rs800292). Individuals carrying the variant I62 are less prone to complement-dysregulation diseases like aHUS, C3G, AMD or dengue hemorrhagic fever $(14,15)$. Furthermore, $\mathrm{FH}^{162}$ showed increased binding affinity for C3b and enhanced cofactor activity (16).

Although the complement system should protect the body against viral infections, its over-activation has been associated with viral pathogenesis, e.g. in hepatitis $C$ (17), dengue virus (18) and coronavirus infections $(19,20)$. Higher levels of C3a and C5a were detected in sera of patients with severe dengue (18) and deposition of complement proteins on hepatocytes was associated with liver damage in fatal cases (21). Recently, the role of complement over-activation in SARS-CoV pathogenesis has been proved. C3 deposition was found in the lungs of SARS-CoV infected mice, while C3 KO mice suffered less from respiratory dysfunction (20). Likewise, C5a accumulation and C3 deposition were observed in lung biopsy samples from COVID-19 patients (19), and enhanced activation of the alternative pathway was associated with a severe outcome of the disease (22). Furthermore, C3a and C5a induce inflammation and are important in initiating the "cytokine storm", contributing to acute lung injury in COVID-19. 
Therefore, anti-complement drugs might be an effective therapy to avoid severe inflammatory response $(23,24)$. Indeed, different pharmacological complement inhibitors, such as $\mathrm{C} 1$ esterase inhibitor (25), anti-C5 antibodies eculizumab, and ravulizumab (23, 26), C3 inhibitor AMY-101 (23) and anti-C5a antibody IFX-1 (27) (the last two still in clinical trials) have been tested to treat severe cases of COVID-19, with promising results. However, the efficacy of these treatments and the best point of the complement activation cascade to target inhibition in COVID-19 patients still needs to be assessed. Furthermore, contrary to spike proteins from a common human coronavirus (HCoVOC43), SARS-CoV-2 spike proteins were shown to activate the complement on cell surfaces mainly through the AP. Addition of FH protected cells from spike proteins-induced complement attack (28), which suggest that complement therapeutics based on $\mathrm{FH}$ activity might be an important alternative.

Although huge efforts are being undertaken to develop complement therapeutics, most are still in clinical development. Anti-C5 antibodies (eculizumab and ravulizumab) are efficient complement therapeutics and the only approved drugs to treat aHUS $(29,30)$. However, these compounds are not as effective in many patients suffering from $C 3 G$ and would not be beneficial to treat severe dengue, because they do not prevent the cleavage of C3 (18). Thus, treatments also regulating the complement at the level of C3 are necessary. In general, anti-C5 antibodies, which block the terminal pathway and complement activity, are associated with a higher susceptibility to infections and are among the most expensive pharmaceuticals in the world (31).

It is therefore essential to generate new alternative therapeutic agents to treat diseases associated with complement dysregulation using approaches to control rather than block complement activation. $\mathrm{FH}$ is the physiological regulator on the level of $\mathrm{C} 3$ and therefore, $\mathrm{FH}$-based therapies could restore homeostasis. However, due to the complexity of this molecule, it is desirable to produce smaller proteins with higher overall regulatory activity. Different fusion proteins including $\mathrm{FH}$ active domains have been developed (32-34). The synthetic multitarget complement regulator MFHR1combines the dimerization and C5-regulatory domains of FHR1 with the C3-regulatory and cell surface recognition domains of $\mathrm{FH}$ to regulate the activation of the complement in the proximal and the terminal pathways. This fusion protein ( $\left.\mathrm{FHR} 1_{1-2}: \mathrm{FH}_{1-4}: \mathrm{FH}_{19-20}\right)$ exhibited a higher overall regulatory activity in vitro compared to $\mathrm{FH}$ or miniFH $\left(\mathrm{FH}_{1-4}: \mathrm{FH}_{19-20}\right)$ and prevented AP deregulation in models of aHUS and C3G (32).

The moss Physcomitrella (Physcomitrium patens) is a suitable production host for pharmaceutically interesting complex proteins, as demonstrated by the successful completion of the clinical trial phase I of a-galactosidase (Repleva AGAL; eleva $\mathrm{GmbH}$ ) to treat Fabry disease (35). MFHR1 and $\mathrm{FH}$ have been produced in moss with full in vitro regulatory activity (36-38).

Physcomitrella's characteristics include genetic engineering via precise gene targeting, growth as a differentiated tissue in a low-cost inorganic liquid medium, long-term genetic stability, industry-scale production in photo-bioreactors $(500 \mathrm{~L})$, homogenous glycosylation profile, high batch-to-batch stability and glycoengineering for improved pharmacokinetics and pharmacodynamics of the biopharmaceutical $(35,39,40)$.

Here, we designed MFHR13 (FHR1 $1_{1-2}: \mathrm{FH}_{1-4}: \mathrm{FH}_{13}: \mathrm{FH}_{19-20}$, Fig. 1b) as a novel multitarget complement regulator produced in the GMP-compliant moss production platform. MFHR13 includes the variant 162 of $\mathrm{FH}$, which we characterized to induce a higher binding to $\mathrm{C} 3 \mathrm{~b}$ and cofactor activity. After structure assessment by in silico modelling, we introduced the SCR $\mathrm{FH}_{13}$, which includes an $\mathrm{N}$-glycosylation site for higher protein stability (41), and contributes to increased flexibility of the molecule and cell surface recognition. MFHR13 was able to protect erythrocytes from complement attack in vitro much more efficiently than C5-binding antibodies, FH or MFHR1 $\left(\mathrm{MFHR}^{\mathrm{V} 62}\right.$ ). Moreover, we could demonstrate that MFHR13, as well as its parental protein FHR1, are able to bind not only $\mathrm{C} 5$ or $\mathrm{C} 5 \mathrm{~b} 6$, but also $\mathrm{C} 6, \mathrm{C} 7, \mathrm{C} 8$ and $\mathrm{C} 9$, providing mechanistic insights into the role of FHR1 as a regulator of the complement system. We propose MFHR13 as a promising future biopharmaceutical to treat complement-associated diseases. 


\section{Results}

The protective polymorphism $\mathrm{V} 62 \mathrm{I}$ is located in the regulatory region of $\mathrm{FH}$, which is involved in C3b-binding and cofactor activity (CA). To confirm the suitability of the 162 variant as part of an improved complement regulator, we tested the influence of this single amino acid exchange on C3b binding and CA of MFHR $1^{162}$ compared to MFHR $1^{\mathrm{V} 62}$, both produced in Physcomitrella.

\section{MFHR1 ${ }^{162}$ was successfully produced in Physcomitrella}

MFHR1 $1^{\mathrm{V} 62}$ was obtained from the moss line P1 (IMSC no.: 40838) (38), and moss lines for the production of MFHR1 $1^{162}$ were established. For this, the $\Delta x t / f t$ moss parental line was used (50). Recombinant proteins produced in this line display $\mathrm{N}$-glycans lacking plant-specific fucoses and xyloses, which might trigger an immune response in patients. After transfection with pAct5MFHR $1^{162}$ and selection, suspension cultures were established for all surviving plants and screened for MFHR $1^{162}$ production via ELISA. $70 \%$ of the lines produced MFHR $1^{162}$ in different concentrations (Supplementary Fig S1). Four of the best producing lines were compared regarding growth and protein productivity at shake-flask scale during 26 days (Supplementary Fig. S2). The best producing line, $\mathrm{N}-179$ (IMSC no.: 40839), was scaled up to a $5 \mathrm{~L}$ stirred bioreactor, where a productivity of $170 \mu \mathrm{g} \mathrm{MFHR} 1^{162} / \mathrm{g}$ FW was achieved (Supplementary Fig. S3). For structure and activity characterization, MFHR1 $1^{162}$ was purified from 8-days-old moss tissue via nickel affinity chromatography followed by anion exchange chromatography. Approximately $500 \mu \mathrm{g} \mathrm{MFHR} 1^{162} / \mathrm{mL}$ were obtained after purification and concentration.

\section{The MFHR1 $1^{162}$ variant has higher C3b binding and cofactor activity}

To analyze the influence of the polymorphism V62I on protein function, we assessed the binding of MFHR1 $1^{\sqrt{62}}$ and MFHR $1^{162}$ to $\mathrm{C} 3 \mathrm{~b}$ and C5, respectively, via ELISA. As expected, there was no difference between both variants in $C 5$ binding $\left(P=0.9328\right.$, Fig. 2a), while MFHR1 $1^{162}$ bound to immobilized C3b significantly better than MFHR1 ${ }^{V 62}(P=0.0437$ Fig. $2 b$, Supplementary Table 2).

$\mathrm{CA}$ of both variants was measured in fluid-phase. Degradation of C3b is characterized by the cleavage of the C3b a'-chain to fragments C3b a'-68, -46, and -43, while C3b $\beta$-chain is not cleaved (Fig. 2c). MFHR1 $1^{162}$ displayed slightly better CA than MFHR1 ${ }^{\mathrm{V} 62}$ (Fig. $2 \mathrm{~d}$ ). Double reciprocal plot and linear regression analysis showed significant differences between them $(P=0.0302$, Fig $2 e)$. Due to the positive influence of 162 in the regulatory activity, we included this variant in MFHR13.

\section{Comparative protein structure modelling approach of MFHR13}

To provide a potent complement biopharmaceutical, structural features that promote the efficacy of the product have to be taken into account: 1) Improving flexibility of the molecule by increasing the distance between $\mathrm{FH}_{4}$ and $\mathrm{FH}_{19}$, which will be important to enhance the biological activity of engineered versions of $\mathrm{FH}$ (57). 2) Improving glycosylation, since it plays an important role in the stability, half-life in the circulation, efficacy and safety of biopharmaceuticals (41). MFHR1 has two glycosylation sites. The first site in $\mathrm{FHR}_{2}$ is partially occupied and the second site located in $\mathrm{FH}_{4}$ is deamidated and thus not glycosylated $(38,58)$, resulting in a high portion of non-glycosylated product. Therefore, we included an additional SCR with an $\mathrm{N}$-glycosylation site to MFHR1 ${ }^{162}$ between $\mathrm{FH}_{4}$ and $\mathrm{FH}_{19}$. The glycosylation sites in $\mathrm{FH}$ are found in SCRs 9, 12, 13, 14, 15, 17 and 18. An interesting domain was $\mathrm{FH}_{13}$ due to the high amount of basic amino acid residues and its electrostatic properties, which suggests it might contain a polyanion (glycosaminoglycans or sialic acid) binding site, thus potentially increasing the host cell surface recognition.

A comparative protein structure modelling approach (Modeller 9.19) was carried out to evaluate the structure of the fusion protein $\mathrm{FHR}_{1-2}: \mathrm{FH}_{1-4}: \mathrm{FH}_{13}: \mathrm{FH}_{19-20}$ and if the $\mathrm{C} 3 \mathrm{~b}$ binding sites are accessible.

To build the model we used crystal structures retrieved from the PDB database corresponding to $\mathrm{FHR}_{1-2}, \mathrm{FH}_{1-4}+\mathrm{C} 3 \mathrm{~b}, \mathrm{FH}_{12-13}, \mathrm{FH}_{19-20}$, and $\mathrm{FH}_{19-20}+\mathrm{C} 3 \mathrm{~d}$. Furthermore, $\mathrm{FH} 1114$ (Model SAXS, $\mathrm{FH}_{11-}$ 14) was used to orient $\mathrm{FH}_{13}$, since $\mathrm{FH}_{14}$ shares about $30 \%$ sequence identity with $\mathrm{FH}_{19}$. Out of 400 models generated, we selected the one with the lowest DOPE score and assessed its quality using the web-based tools ProSa and PROCHECK. The overall quality of the model was acceptable and 
in the range of all available structures on PDB. According to the local model quality, where the energy is plotted as a function of residues' position in the sequence, problematic parts of the model (characterized by positive energy values) were located in some linkers, such as the linker between $\mathrm{FH}_{4}$ and $\mathrm{FH}_{13}$. However, this is also observed in linkers of the native proteins of this family (Supplementary Fig. S4a, b). Moreover, according to the Ramachandran plot, 97.6\% of amino acid residues are in favored regions, $1.3 \%$ in allowed regions and only $1.1 \%$ in outlier regions (Supplementary Fig. S4c). Our model indicates that the introduction of $\mathrm{FH}_{13}$ may not affect biological activity and might confer higher flexibility to the molecule (Fig. 3a). Finally, the MFHR13 model was superimposed with the structures $2 \mathrm{WII}$ and $2 \mathrm{XQW}$, which correspond to $\mathrm{FH}_{1-4}$ bound to $\mathrm{C} 3 \mathrm{~b}$ and $\mathrm{FH}_{19-20}$ to $\mathrm{C} 3 \mathrm{dg}$, respectively. The natural linkers are flexible enough to allow $\mathrm{FH}_{13}$ to fold back over in such a way that allows $\mathrm{FH}_{1-4}$ and $\mathrm{FH}_{19}$ to interact simultaneously with one C3b molecule (Fig. 3b). Furthermore, there is a striking electropositive patch extending over one face of $\mathrm{FH}_{13}$ to $\mathrm{FH}_{20}$ (Fig. $3 \mathrm{c}$ ), which might enhance the affinity to host cell surfaces.

\section{Moss-produced MFHR13 is correctly synthesized and efficiently glycosylated}

For the production of MFHR13 (FHR1 1 1-2 $\mathrm{FH}_{1-4}: \mathrm{FH}_{13}: \mathrm{FH}_{19-20}$ ), the $\Delta x t / f t$ moss line was transformed with the pAct5-MFHR13 construct. Selection and screening of plants producing MFHR13 was performed following the same procedure as described above for MFHR $1^{162}$. From 98 surviving plants, $45 \%$ produced MFHR13 in different levels as screened by ELISA (Supplementary Fig. S5). For the best producing line N13-49 (IMSC no.: 40840) around $70 \mu \mathrm{g}$ MFHR13/g FW were achieved in the $5 \mathrm{~L}$ bioreactor cultivation, which correspond to $7 \mathrm{mg} \mathrm{MFHR13}$ after 8 days (Supplementary Fig. S6).

Approximately $200 \mu \mathrm{g}$ MFHR13/mL were obtained after purification (Fig. 4a). The concentration was measured by ELISA and the correct ratios between MFHR13, MFHR $1^{162}$ and MFHR $1^{\mathrm{V} 62}$ were further confirmed by semi-quantitative Western blot (Fig. 4b).

MFHR13 migrated at approximately $70 \mathrm{kDa}$ and the integrity of the protein was confirmed by Western blot and mass spectrometry (MS) (Fig. 4a-c). Via MS, MFHR13 was identified with a sequence coverage of $64 \%$. The correct introduction of SCR13 of $\mathrm{FH}$, together with its linkers, and the presence of isoleucine at position 193 were confirmed (Fig. 4c). The glycosylation site (NIS) located in the FHR $1_{2}$ in MFHR13 was around $65 \%$ occupied with the pattern described in Fig 4d. As already described for moss-produced MFHR1 and human $\mathrm{FH}$, the glycosylation site located on $\mathrm{FH}_{4}$ in MFHR13 was deamidated and not glycosylated. The new glycosylation site (NCS) introduced within $\mathrm{FH}_{13}$ was fully glycosylated, as we did not detect the unglycosylated peptide. Around $85 \%$ of all glycans comprised mature complex-type glycans (GnGn, GnAF, AAFF) and only 15\% of immature glycans with terminal mannose (Fig. 4d).

\section{MFHR13 exhibits enhanced heparin-binding}

One important feature of complement regulators is the ability to bind to polyanions such as glycosaminoglycans and sialic acids on host cell surfaces and protect them from complement attack. The ability of MFHR13 to bind to the polyanion heparin was evaluated by an ELISA-based method, and compared to MFHR $1^{\mathrm{V} 62}$, MFHR1 $1^{162}$ and $\mathrm{hFH}$, respectively. As expected, there were no differences in heparin-binding between MFHR1 $1^{\mathrm{V} 62}$ and MFHR1 $1^{162}$. In contrast, MFHR13 bound to heparin twice as strong as MFHR1 ${ }^{\mathrm{V} 62}$ and MFHR1 ${ }^{162}(\mathrm{P}<0.0001)$, (Fig. 5a, Supplementary Table 3). This can be attributed to the presence of $\mathrm{FH}_{13}$. Heparin-bound $\mathrm{hFH}$ was only detected at the highest concentration tested $(25 \mathrm{nM})$, indicating approximately 4 -fold lower affinity to heparin than MFHR13 (Fig.5b, $\mathrm{P}<0.0001$ ).

\section{MFHR13 regulates complement activation at the level of $\mathrm{C} 3$}

Binding of MFHR13 to immobilized C3b was evaluated via ELISA in comparison to MFHR1 ${ }^{162}$, to evaluate the influence of $\mathrm{FH}_{13}$ on this activity. We found that both proteins bound to $\mathrm{C} 3 \mathrm{~b}$ with similar affinity (Fig. 6a; $P=0.8426$, Supplementary Table 4).

MFHR13 is able to support the FI-mediated cleavage of C3b a'-chain. MFHR13 showed similar fluid-phase CA in independent experiments as compared to MFHR1 ${ }^{162}$, however, hFH had a higher $\mathrm{CA}$ than both synthetic regulators. (Fig. $6 \mathrm{~b}, \mathrm{c})\left(\mathrm{P}=0.0025\right.$ and 0.0040 for MFHR13 and MFHR1 $1^{162}$, respectively). 
The ability of the regulators to dissociate preformed C3 convertases, known as decay acceleration activity (DAA), was evaluated in an ELISA-based method. Increasing equimolar amounts of the regulators MFHR13, MFHR $1^{162}$, MFHR $1^{\mathrm{V} 62}$, or $\mathrm{hFH}$, respectively, were incubated with $\mathrm{C} 3$ convertase $(\mathrm{C} 3 \mathrm{bBb})$ and $\mathrm{Bb}$ fragment displacement was detected. The DAA of MFHR13, with an $\mathrm{IC}_{50}$ of $2.7 \mathrm{nM}$, was similar to that of $\mathrm{hFH}\left(\mathrm{IC}_{50} 3.8 \mathrm{nM}\right)(\mathrm{P}=0.2022)$, but it significantly exceeded the activity of MFHR1 $1^{162}$ and MFHR1 ${ }^{\mathrm{V} 62}\left(\mathrm{IC}_{50} 7.8\right.$ and $9.4 \mathrm{nM}$ respectively) $(\mathrm{P}<0.0001)$. (Fig. 6d, Supplementary Table 5)

\section{MFHR13 blocks the terminal pathway of complement FHR1 and MFHR13 bind to C5, C5b6, C6, C7, C8 and C9}

FHR1 and MFHR1 are able to interact with C5 (32). Binding of MFHR13 to immobilized C5 was evaluated via ELISA in comparison to MFHR $1^{162}$. There was no significant difference after fitting the data with 4PL nonlinear regression model (Fig. 7a; $\mathrm{P}=0.2565$ ).

Further, we tested the binding of MFHR13, the MFHR1 variants, FHR1 and hFH to C5b6 and the other proteins involved in MAC formation. Immobilized C5b6, C6, C7, C8 and C9, and C3b and C5 as positive controls, were incubated with $25 \mathrm{nM}$ of MFHR13 or MFHR1-variants (8x His-tag) or $50 \mathrm{nM}$ FHR1 (6x His-tag) and bound protein was detected with anti-His-tag antibodies. Due to the differences in the amount of histidine in the tag, FHR1 cannot be quantitatively compared to the moss-produced regulators. Due to the lack of His-tag, binding of $\mathrm{hFH}$ to the complement proteins was evaluated separately using anti-FH polyclonal antibodies and compared with MFHR1 ${ }^{\mathrm{V} 62}$. As expected, FH bound only to C3b (Fig. 7b). In contrast, MFHR13, MFHR1 variants and FHR1 bound to all complement proteins involved in MAC formation (Fig. 7c). Here, we proved that FHR1 binds not only to $\mathrm{C} 3 \mathrm{~b}, \mathrm{C} 5$ and $\mathrm{C} 5 \mathrm{~b} 6$ but also to $\mathrm{C} 6, \mathrm{C} 7, \mathrm{C} 8$ and $\mathrm{C} 9$, which contributes to the mechanistic understanding of FHR1 as complement regulator.

\section{MFHR13 prevents hemolysis by blocking MAC formation from C5b6}

The C5-regulatory activity of FHR1 is still being discussed because of difficulties in separating C3 and C5-regulatory activities in vivo. FHR1 and MFHR1 were shown to bind C5b6 and prevent MAC formation in vitro $(10,32)$. Here, we evaluated this activity of moss-made MFHR13, using a serumfree approach and compared their activity to FHR1, hFH and eculizumab. For this, the complex C5b6 was incubated with the regulators $(1 \mu \mathrm{M})$ followed by the addition of sheep erythrocytes and the terminal complement proteins C7, C8, and C9. Inhibition of C5b-9 formation was indirectly measured by hemolysis. The surface of sheep erythrocytes is rich in sialic acid and a good model for host-cell surfaces to test regulation of complement attack.

MFHR13, similar to FHR1, protected sheep erythrocytes from complement attack, reducing cell lysis by approximately $70 \%$, while $\mathrm{hFH}$, eculizumab, BSA and purified extract from the parental line $(\Delta x t / f t)$ lacked such positive effects (Fig. $7 d$ ).

The terminal pathway is initiated upon cleavage of $\mathrm{C} 5$ to $\mathrm{C} 5 \mathrm{~b}$, or independently from convertases when C5 binds to densely C3b-opsonized surfaces and acquires a C5b-like conformation (5). Subsequently, MAC formation begins with the binding of C5b, or C5b-like activated C5, to C6. Here, we evaluated the ability of MFHR13 to inhibit the C5 priming on opsonized sheep erythrocytes. Human FH did not differ significantly from the negative controls BSA or purified extract from $\Delta x t / f t$, and could barely inhibit hemolysis. Under these conditions, the sample treated with eculizumab supported hemolysis, which was unexpected and differs from what was reported before when higher concentrations of complement proteins and antibody have been used (5). In contrast, MFHR13 (700 nM) reduced cell lysis by $60 \%$, efficiently protecting sheep erythrocytes from convertase-independent C5 activation and MAC formation, while FHR1 reduced lysis by $\square 33 \%$.

Interestingly, the hemolysis induced by C5b6-C9 was ( $\square$ 130\%) higher than the one induced by convertase-independent activation of $\mathrm{C} 5$, even when the concentrations of complement proteins involved in the MAC formation were almost 20 times higher in the latter assay (Supplementary Fig. S7). 


\section{MFHR13 exhibits efficient regulatory activity on activated AP}

The ability of MFHR13 to inhibit the formation of the C5b-9 complex (TCC) after activation of the AP with LPS in normal human serum (NHS) was evaluated by an ELISA-based assay and compared to MFHR1 $1^{162}$, MFHR1 ${ }^{\mathrm{V} 62}$, $\mathrm{hFH}$ and the C5-blocking antibody eculizumab. MFHR13 inhibited TCC formation very efficiently, exhibiting 37-fold and 2-fold the activity of $\mathrm{hFH}$ and eculizumab respectively (Fig. 8a; Table 1). MFHR13 was slightly better than MFHR1 ${ }^{\mathrm{V} 62}$ and no significant difference was observed compared to MFHR1 $1^{162}$.

\section{MFHR13 protects sheep erythrocytes from complement-induced lysis}

Finally, we tested the ability of the moss-produced regulators to protect sheep erythrocytes from complement attack. The AP was spontaneously activated by addition of MgEGTA to NHS depleted of $\mathrm{FH}$. In this in vitro-model for host cell surfaces, MFHR1 ${ }^{\mathrm{V} 62}$ and MFHR1 $1^{162}$ were as active as $\mathrm{hFH}$, whereas MFHR13 protected erythrocytes from complement attack more efficiently than the other factors, MFHR1 ${ }^{\mathrm{V} 62}$ (3.7-fold), MFHR1 ${ }^{162}$ (2.9-fold), hFH (4.2-fold), and eculizumab (26-fold) (Fig. 8b, Table 1). 


\section{Discussion}

Complement dysregulation due to mutations in complement genes, autoantibodies against complement proteins or over-activation in response to certain viral infections leads to a long list of diseases. C3G, PNH and aHUS are examples where complement is the main driver of the disease $(8,13,59)$. Although the development of drugs to regulate the complement response and restore homeostasis is of huge interest, $\mathrm{C} 1$ esterase inhibitor and blocking antibodies against C5 are the only available so far (29). FH is a physiological regulator of the complement system, but truncated versions of it, such as mini-FH (AMY201, Amyndas) (57), have been proposed as better therapeutics because of an enhanced overall regulatory activity compared with $\mathrm{FH}$. Moreover, drugs able to regulate the activation cascade at several levels might be especially interesting to increase efficiency. MFHR1 combines the regulatory domains of $\mathrm{FHR} 1$ and $\mathrm{FH}$, and exhibits a higher regulatory activity than mini- $\mathrm{FH}\left(\mathrm{FH}_{1-4}: \mathrm{FH}_{19-20}\right)$ (32). Our studies led to the development of MFHR13 as a potential therapeutic for complement dysregulation.

For MFHR13 design, we first considered the polymorphism V62I. The substitution of valine by isoleucine within SCR1 of $\mathrm{FH}$ is located in the regulatory domain. $\mathrm{FH}^{162}$ is associated with lower risk for aHUS and C3G (60). Although both amino acids are biochemically similar, and both FH variants can fold correctly, the substitution has structural consequences: The FH SCRs are tightly folded forming a compact hydrophobic core, where the residue 62 is buried, and the additional methylene group from isoleucine triggers a small conformational rearrangement. Additionally, the $\mathrm{FH}^{162}$ is slightly more thermally stable and rigid than the $\mathrm{FH}^{\mathrm{V} 62}(61)$. We studied the influence of this amino acid exchange on the activity of the synthetic complement regulator MFHR1. Binding to immobilized $\mathrm{C} 3 \mathrm{~b}$ and cofactor activity of MFHR $1^{162}$ were significantly higher than that of MFHR $1^{\mathrm{V} 62}$. Therefore, we included the more active variant 162 in MFHR13.

The importance of protein glycosylation on the stability, efficacy and half-life of biopharmaceuticals in serum is well known (41). Deglycosylated proteins were shown to be inactive in vivo (62). MFHR1 ${ }^{\mathrm{V} 62}$ has a higher regulatory activity than $\mathrm{hFH}$ in vitro but was surpassed by $\mathrm{hFH}$ in vivo, which was attributed to a reduced half-life in the circulation (32). MFHR1 ${ }^{\text {V62 }}$ is only partially glycosylated, due to the nature of the $\mathrm{N}$-glycosylation sites present in this fusion protein, which are not or only partially glycosylated in the physiological counterparts FH and FHR1, respectively (38). To support protein stability and prolong half-life in serum we aimed to include an additional $N$ glycosylation site in the new MFHR. For this purpose, we searched for glycosylated SCRs from FH, which beyond achieving glycosylation without the addition of artificial sequences would increase the distance between $\mathrm{SCRs} \mathrm{FH}_{4}$ and $\mathrm{FH}_{19}$ in the regulator. This distance has been postulated before to be crucial for the flexibility and the activity of mini-FH (57).

We proposed the introduction of $\mathrm{FH}_{13}$ with its natural linkers to generate the new molecule MFHR13. $\mathrm{FH}_{13}$ harbors many striking characteristics: Apart from displaying an $\mathrm{N}$-glycosylation site, it is the smallest SCR in FH with the most flexible linkers and one of the most electrostatic positive domains. It has an unusual distribution of charged groups with a net charge of +5 , similar to $\mathrm{FH}_{7}$ and $\mathrm{FH}_{20}(63)$. We hypothesized that the host cell surface recognition could be enhanced by adding this SCR. A comparative protein structure modelling approach supported our hypothesis, since $\mathrm{FH}_{13}$ was completely exposed with a positive electrostatic patch extending towards $\mathrm{FH}_{20}$. This feature may increase the affinity to cell surfaces due to electrostatic interactions and thus stabilize the cell surface-binding site in $\mathrm{FH}_{20}$.

The production of this complement regulator was carried out in moss bioreactors, due to the advantages offered by this system. MS analysis revealed that the $\mathrm{FH}_{13}-\mathrm{N}$-glycosylation site was fully occupied with more than $85 \%$ mature complex-type $N$-glycans, predominantly $\mathrm{GnGn}$ and around $15 \%$ carrying the Lewis A epitope. Although this structure is not desired, the gene responsible for the generation of this structure was identified in moss and can be eliminated by gene targeting (64). In order to increase the half-life in the circulation, $\mathrm{N}$-glycans still need to be terminally sialylated to avoid rapid clearance from circulation (65). Stable protein sialylation is feasible in Physcomitrella (52), although the efficiency should still be improved.

In analogy to $\mathrm{FH}, \mathrm{MFHR} 13$ should protect host cells against complement attack, directing the complement regulatory activity to the cell surface by interaction with polyanions. Therefore, we 
tested the binding to heparin of MFHR13 compared to MFHR1 $1^{162}$, our control lacking FH $\mathrm{F}_{13}$. MFHR13 binds significantly better to heparin than MFHR1 ${ }^{162}$, indicating that $\mathrm{FH}_{13}$ retains the function of the polyanion binding site described recently for $\mathrm{FH}_{11-13}(9)$. Moreover, MFHR13 binds to heparin much better than $\mathrm{hFH}$.

Next, we tested the regulatory activity of MFHR13 at the level of C3. From our protein structure modelling, we expected an enhanced binding of MFHR13 to C3b due to increased flexibility of the molecule. In addition, a weak C3b binding site localized to $\mathrm{FH}_{13-15}$ was described recently (9). MFHR13 binds efficiently to C3b, however, we could not detect significant differences to MFHR $1^{162}$. This indicates that $\mathrm{FH}_{13}$ alone is not enough to build the C3b-binding site described for $\mathrm{FH}_{13-15}$.

MFHR13 displayed similar cofactor activity in fluid phase to MFHR1 ${ }^{162}$, while hFH outperformed both, possibly due to small steric hindrances generated by the dimerization domains present in FHR1 ${ }_{1-2}$. MFHR13 had a similar decay acceleration activity compared to $\mathrm{hFH}$ and significantly higher than MFHR1 $1^{162}$ or MFHR $1^{\mathrm{V} 62}$. Our results suggest that MFHR13 may benefit from the space between $\mathrm{FH}_{4}$ and $\mathrm{FH}_{19}$ to bind to $\mathrm{C} 3 \mathrm{~b}$ using both sites simultaneously, which could increase the decay of the convertases $(\mathrm{C} 3 \mathrm{bBb})$.

We demonstrated that FHR1, MFHR13 and the MFHR1 variants are able to bind not only to C5 and C5b6, but also to C6, C7, C8 and C9. The binding to C8 and C9 was significantly higher compared to $\mathrm{C} 5 \mathrm{~b} 6$, which suggest that regulation is not only mediated through C5b6-complex binding, as currently assumed (12). Our observations indicate an FHR1 activity resembling the function of vitronectin, which is a soluble regulator of the MAC (66), and thus contributes to the understanding of the mechanism of action of FHR1.

To distinguish the specific activity on $\mathrm{C} 5$ level from overall regulation, we evaluated the inhibition of the C5b-9 complex (MAC) formation on sheep erythrocytes in a serum-free approach using C5b6, C7, C8 and C9. We could demonstrate the activity of MFHR13 at this level of activation, which has to be attributed to the presence of the FHR1 $1_{1-2}$ as described previously $(10,32)$.

C5 can be enzymatically activated by $\mathrm{C} 3$ convertases or non-enzymatically by conformational changes when bound to highly C3b- or C4b-opsonized surfaces (5). In contrast to enzymatic activation, conformational $\mathrm{C} 5$ activation cannot be prevented by eculizumab, explaining the residual hemolysis observed in PNH patients treated with adequate levels of this C5 inhibitor (5). As opposed to eculizumab, MFHR13 could inhibit convertase-independent activation of C5 and MAC formation on C3b-opsonized sheep erythrocytes exposed to C5-C9. This mechanism of MAC formation, however, led to a weaker hemolysis than the one induced by C5b6-C9, even at higher concentrations of complement components in the assay, and its physiologic role should be further studied.

The regulatory activity of FHR1 at the level of C5 at physiologic concentrations is controversial (33, 67), however, the physiological concentration of FHR1 itself is still under debate (68). Moreover, it is feasible that FHR1 concentrations are elevated during infection, as suggested by increased expression of the FHR1 gene in zebrafish exposed to LPS (69). Here, we used a molar excess of FHR1 and MFHR13 with respect to MAC components to inhibit C5b6-C9 or C5-C9 mediated hemolysis, but we used a concentration of FHR1 within its physiological range $(0.1-2.7 \mu \mathrm{M})(68)$.

We consider that the presence of the SCRs $\mathrm{FHR} 1_{1-2}$ with a dimerization interface represents an important feature in MFHR13, as the regulatory activity at C5 level is fundamental and coordinates with $\mathrm{FH}$ activity at the level of $\mathrm{C} 3$. This is especially the case when the complement system has been activated by a pathogen, as observed in FHR1-homolog ${ }^{-/-}$mice, which exhibited higher C3a and C5a concentrations, severe inflammation and blood coagulation, leading to organ injury after LPS-induced complement activation (70).

We tested the overall regulatory activity in an ELISA-based assay, and in a cell-based assay by measuring the inhibition of hemolysis caused by the activation of the whole cascade. MFHR13 regulates the C5b-9 complex formation significantly more effectively than $\mathrm{hFH}$ when AP is activated by LPS in normal human serum. Although we could not demonstrate significant differences between MFHR $1^{162}$ and MFHR13 in this assay, they outperformed eculizumab and FH activities by a factor of 2 and 37, respectively. Furthermore, MFHR13 protected sheep erythrocytes from 
hemolysis caused by complement attack, exhibiting 4-, 3-, and 26-fold the regulatory activity of hFH MFHR1 versions and eculizumab, respectively. Since the surfaces of sheep erythrocytes are rich in sialic acid, we assume that the higher affinity of MFHR13 to polyanions might explain the higher local regulatory activity on cell surfaces.

SARS-CoV-2 spike proteins can bind to polyanionic glycosaminoglycans on cell surfaces and overactivate the AP, probably by displacing $\mathrm{FH}$; however, exogenous $\mathrm{FH}$ was shown to protect cells from spike protein-induced complement attack (28). Since MFHR13 binds to polyanions very efficiently and is a potent regulator of the AP, it might represent a promising alternative for COVID19 therapy.

In summary, we designed MFHR13, a novel synthetic multi-target complement regulator, and produced it in moss bioreactors. MFHR13 is a glycoprotein that regulates the overall complement activity around 37 times as efficient as native human $\mathrm{FH}$, and twice as much as eculizumab, without blocking the complement response completely. Taken together, MFHR13 is a potential therapeutic agent for diseases such as C3G and aHUS, and might also be of interest for different viral pathogenesis where an over-activation of the complement system is involved, such as dengue and COVID-19.

\section{Material and Methods}

\section{Comparative protein structure modelling approach}

To predict the 3D structure and $\mathrm{C} 3 \mathrm{~b}$-binding capacity of a new multitarget complement regulator, MFHR13 (FHR1 1-2: $\mathrm{FH}_{1-4}: \mathrm{FH}_{13}: \mathrm{FH}_{19-20}$ ), we used the template-based modelling implemented in Modeller 9.19 (42).

High-resolution crystal and NMR structures for 17 of 20 domains of human $\mathrm{FH}$ are available in the Protein Data Bank (PDB). To build the model, we used the following structures as templates (PDB accessions): 3ZD2 (FHR1 $\left.1_{1-2}\right)$, 2WII $\left(\mathrm{FH}_{1-4}+\mathrm{C} 3 \mathrm{~b}\right)$, 2KMS (FH $\left.12-13\right), 2 \mathrm{G} 7 \mathrm{I}\left(\mathrm{FH}_{19-20}\right), 3 \mathrm{SW0}\left(\mathrm{FH}_{18-20}\right)$, 2XQW $\left(\mathrm{FH}_{19-20}+\mathrm{C} 3 \mathrm{~d}\right.$ ), and a SAXS model for $\mathrm{FH}_{11-14}$ (Accession in Small Angle Scattering Biological Data Bank (SASBDB): SASDAZ4). As the orientation between adjacent SCR domains is difficult to predict, some restrictions were added to orient the template structures appropriately. These restrictions were obtained by measuring distances $\mathrm{C} \alpha-\mathrm{Ca}$ between adjacent SCRs in PDB structures such as 2WII, 3SW0 using the PyMOL Molecular Graphics System, Version 2.0, Schrödinger, LLC (PyMOL 2.0). Some additional restraints between $\mathrm{FH}_{4}$ and $\mathrm{FH}_{19}$ were taken into account, after superimposing the structures $2 \mathrm{WII}$ and $2 \mathrm{XQW}$, which correspond to $\mathrm{FH}_{1-4}$ with C3b and $\mathrm{FH}_{19-20}$ with $\mathrm{C} 3 \mathrm{~d}$ respectively.

The alignment of MFHR13 was done using also a structure for $\mathrm{FH}_{11-14}$, derived from SAXS information (SASDAZ4). $\mathrm{FH}_{14}$ was aligned with $\mathrm{FH}_{19}$ because they share a sequence identity of $30 \%$, and it would allow orienting $\mathrm{FH}_{13}$. The module Automodel from modeler 9.19 was used to generate 100 models. The loop regions were refined using the loopmodel class, and 4 models with loop refined were built for every standard model (total: 400 models). Optimization of the objective function was done using 300 iterations with the conjugate gradient technique and molecular dynamics with simulated annealing to refine the model. The best models were chosen comparing the Discrete Optimized Protein Energy (DOPE) score. The quality of the models was evaluated using the Ramchandran Plot SAVeS Server (PROCHECK) (43) (https://services.mbi.ucla.edu/SAVES/), ProsaWEB (https://prosa.services.came.sbg.ac.at/prosa.php) (44). 3D structures were visualized with PyMol 2.0.

\section{Generation of plasmid constructs}

First, the vector pAct5-MFHR1 $1^{162}$, coding for MFHR1 $1^{162}$, a MFHR1 variant with isoleucine instead of valine at position 193, which corresponds to position 62 of factor $\mathrm{H}$, was created. This vector was obtained via site-directed mutagenesis using the Phusion Site-Directed Mutagenesis Kit (Thermo Fisher Scientific, Waltham, MA, USA) according to the manufacturer's instructions. The vector pAct5-MFHR1 (38)was used as template with the primers MFHR1_162_fwd and MFHR1_I62_rev 
(Supplementary Table 1), exchanging a single nucleotide (GTA to ATA, V62I). In this vector the expression of MFHR $1^{162}$, fused to a C-terminal $8 x$ His-tag, is driven by the $5^{\prime}$ region, including the $5^{\prime}$ intron, of the PpActin5 gene (45) and the cauliflower mosaic virus (CaMV) 35S terminator. For proper posttranslational modifications, the recombinant protein was targeted to the secretory pathway by the aspartic proteinase signal peptide from $P$. patens, PpAP1 (46). The hpt cassette (47) is present to select the transformed plants with hygromycin.

For the production of MFHR13 the expression construct pAct5-MFHR13, based on pAct5MFHR $1^{162}$, was generated using Gibson assembly (48). For this, the sequence coding for SCR $\mathrm{FH}_{13}$, together with its natural flanking linkers, was amplified from plasmid $\mathrm{pFH}(36)$ with the primers SCR13 overlapSCR4_fwd and SCR13_overlapSCR19_rev. This fragment was inserted in pAct5MFHR $1^{\text {T62 }}$, previously amplified with primers SCR4_overlapSCR13_rev and SCR19_overlapSCR13_fwd (Supplementary Table 1), designed to exclude the linker between $\mathrm{FH}_{4}$ and $\mathrm{FH}_{19}$ and overlapping the sequence of the linkers from $\mathrm{FH}_{13}$. PCRs were performed with Phusion TM High-Fidelity DNA Polymerase (Thermo Fisher Scientific). Assembled vectors were verified by sequencing.

\section{Plant material, culture, transformation procedure and protein production}

Physcomitrella (Physcomitrium patens) was cultivated as previously described (47) on Knop ME medium (49). Lines producing MFHR13 or MFHR $1^{162}$ were obtained by stable transformation of the $\Delta x t / f t$ moss line (IMSC no.: 40828), in which the genes coding for $\alpha 1,3$ fucosyltransferase and the $\beta 1,2$ xylosyltransferase are knocked out (50).

Moss protoplast isolation, polyethylene glycol-mediated transfection (using $50 \mu \mathrm{g}$ of linearized plasmid DNA), regeneration and selection were performed as previously described (47).

Plants surviving the selection were transferred to liquid medium and after one month of weekly propagation, moss lines were screened for the production of the proteins of interest. For this, 6days-old moss suspension cultures were vacuum-filtrated and $30 \mathrm{mg}$ fresh weight (FW) material were analyzed by ELISA. To analyze the time course of growth and production of the protein, lines were inoculated in triplicates at $200 \mathrm{mg} / \mathrm{L} \mathrm{DW}$ and samples were taken every 3 days for 26 days.

The best MFHR1 ${ }^{162}$ and MFHR13 producing moss lines, respectively, were scaled up to stirred tank bioreactors $(5 \mathrm{~L})$, operated in batch for $8-12$ days with the following conditions: $\mathrm{pH} 4.5$, at $22^{\circ} \mathrm{C}$, aerated with $0.3 \mathrm{vvm}$ air supplemented with $2 \% \mathrm{CO}_{2}$, stirred with $500 \mathrm{rpm}$, continuous light with an intensity of $160 \mu \mathrm{mol} \mathrm{m} \mathrm{s}^{-1}$ (day $0-2$ ) and $350 \mu \mathrm{mol} \mathrm{m}^{-2} \mathrm{~s}^{-1}$ (day 2-8). The growth medium was supplemented with 1 -naphthaleneacetic acid (10 $\mu \mathrm{M} N A A)$ at day 3 according to (38).

\section{Purification of moss-produced recombinant proteins}

MFHR13 and MFHR1 variants (MFHR1 $1^{162}$ and MFHR $1^{\mathrm{V} 62}$ ), respectively, were extracted from vacuum-filtrated plant material. For this, $4 \mathrm{~mL}$ binding buffer $\left(75 \mathrm{mM} \mathrm{Na}_{2} \mathrm{HPO}_{4}, 0.5 \mathrm{M} \mathrm{NaCl}, 20 \mathrm{mM}\right.$ imidazole, $0.05 \%$ Tween-20, 10\% glycerol, $1 \%$ protease inhibitor (P9599, Sigma-Aldrich), $\mathrm{pH} 7.0$ ) were added per gram FW and the suspension was disrupted with an ULTRA-TURRAX® $(10,000$ $\mathrm{rpm}$ ) and simultaneous sonication (ultrasonic bath) for $10 \mathrm{~min}$ on ice. After two consecutive centrifugation steps $\left(4,500 \times \mathrm{g}\right.$ for $3 \mathrm{~min}$ and $20,000 \times \mathrm{g}$ for $10 \mathrm{~min}$ at $\left.8^{\circ} \mathrm{C}\right)$ the supernatant was filtered through $0.22 \mu \mathrm{m}$ PES filters (Roth).

For chromatographic purification, the filtrate was loaded onto a $1 \mathrm{~mL}$ HisTrap FF column, using the ÄKTA system (Cytiva) at $1 \mathrm{~mL} / \mathrm{min}$. The column was washed with 30 column volumes (CV) of binding buffer and 3\% elution buffer (100\%: $100 \mathrm{mM} \mathrm{Na}_{2} \mathrm{HPO}_{4}, 0.5 \mathrm{M} \mathrm{NaCl}, 500 \mathrm{mM}$ imidazole, $10 \%$ glycerol, $\mathrm{pH} 7.4)$. The protein was eluted using a stepwise gradient ( $6 \%$ elution buffer for 10 $\mathrm{CV}, 17 \% 5 \mathrm{CV}, 27 \% 3 \mathrm{CV}, 100 \% 6 \mathrm{CV}$ ) and collected in $0.5 \mathrm{~mL}$ fractions. The first five fractions obtained with $100 \%$ elution buffer were pooled and diluted with Tris buffer $\mathrm{pH} 7.6$ to reach $50 \mathrm{mM}$ $\mathrm{NaCl}$ and loaded onto a $1 \mathrm{~mL}$ HiTrap Q HP column (Cytiva). MFHR13, MFHR1 ${ }^{162}$ or MFHR1 ${ }^{\text {V62 }}$ were eluted using a linear gradient (3-100\%) and elution fraction containing the protein of interest (screened by ELISA and Western blot) were pooled and dialyzed against Dulbecco's phosphatebuffered saline (DPBS) in Slide-A-Lyzer ${ }^{\circledR}$ MINI Dialysis Devices, $20 \mathrm{~K}$ MWCO (Thermo Fisher 
Scientific). Proteins were concentrated by ultrafiltration using Vivaspin 2, 10 kDa MWCO (PES membrane; Sartorius).

\section{Protein quantification and Immunoblotting}

MFHR13 and MFHR1 variants were quantified by ELISA using a modified protocol (36): In order to quantify the fusion proteins using plasma-derived $\mathrm{FH}(\mathrm{hFH})$ standard as a reference, a polyclonal antibody against the whole $\mathrm{FH}$ was avoided, due to the differences in the protein structure and molecular weight between $\mathrm{FH}$ and the fusion proteins. Instead, a detection antibody against the $\mathrm{FH}_{1-4}$, domains shared by all the proteins of interest, was used.

Microtiter plates (Nunc Maxisorp, Thermo Fisher Scientific) were coated overnight at $4^{\circ} \mathrm{C}$ with GAU 018-03-02 (Thermo Fisher Scientific), a monoclonal antibody that recognizes $\mathrm{FH}_{20}(1: 2,000$ in coating buffer (1.59 $\left.\mathrm{g} / \mathrm{l} \mathrm{Na}_{2} \mathrm{CO}_{3}, 2.93 \mathrm{~g} / \mathrm{l} \mathrm{NaHCO} 3, \mathrm{pH} 9.6\right)$ ) and blocked with sample buffer (2\% BSA in TBS (Tris Buffer Saline) supplemented with 0.05\% Tween-20). Samples and hFH standard (hFH, CompTech; $12.9 \mathrm{pM}-1.1 \mathrm{nM}$ ) were diluted in sample buffer and incubated for $90 \mathrm{~min}$ at $37^{\circ} \mathrm{C}$ The proteins of interest were detected by a polyclonal anti- $\mathrm{FH}_{1-4}(1: 15,000$ in washing buffer (1\% BSA in TBS supplemented with $0.05 \%$ Tween-20) (51) and anti-rabbit coupled to horseradish peroxidase (HRP) (NA934; Cytiva, 1:5,000 in washing buffer).

The ratio between MFHR13, MFHR $1^{162}$ and MFHR1 $1^{\mathrm{V} 62}$ concentration was also compared with semiquantitative Western blots. SDS-PAGE on 7.5 or $10 \%$ gels, Coomassie staining and Western blot analysis were performed as described before (38).

\section{Glycosylation analysis}

MFHR13, purified as described above, was used for MS analysis. In brief, duplicate samples of purified MFHR13 were reduced and alkylated as previously described (52), subjected to SDSPAGE and subsequently stained with PageBlue ${ }^{\circledR}$ (Thermo Fisher Scientific). Bands corresponding to the expected size of MFHR13 were excised and distained. Digestion was performed overnight with $0.2 \mu \mathrm{g}$ trypsin (Trypsin Gold, Promega) and $0.2 \mu \mathrm{g}$ chymotrypsin (sequencing grade, Promega) simultaneously at $37^{\circ} \mathrm{C}$. Peptides were recovered and desalted using $\mathrm{C} 18$ StageTips (Thermo Fisher Scientific) and measured on a QExactive Plus Orbitrap (Thermo Fisher Scientific) as described in (38). Raw data was processed with Mascot Distiller V2.7.10 and a database search was performed using Mascot server V2.7 (Matrix Science). Processed spectra from both duplicates were searched against a database containing all Physcomitrella protein models (V3.3, (53)) as well as the sequence of MFHR13 and simultaneously against a database containing sequences of known contaminants (269 entries, available on request) using a precursor mass tolerance of $5 \mathrm{ppm}$ and a fragment mass tolerance $0.02 \mathrm{Da}$. As variable modifications $\mathrm{Gln}->$ pyroGlu (N-term. Q) $-17.026549 \mathrm{Da}$, dehydration Glu->pyroGlu (N-term. E) -18.010565 Da, oxidation +15.994915 Da (M), deamidation +0.984016 Da (N), GnGn +1298.475961 Da (N) were specified. Carbamidomethyl $+57.021464 \mathrm{Da}(\mathrm{C})$ was set as fixed modification. Search results were loaded in Scaffold5 software (Proteome Software, Inc.) and a threshold of $1 \%$ FDR at the protein level and $0.1 \%$ at the peptide level with a minimum of 2 identified peptides was specified.

Glycopeptides were identified from processed mgf files as described in (52) using a custom Perl script. Quantitative values for identified glycopeptides were obtained from the allPeptides.txt file (available on request) from a default MaxQuant (V1.6.0.16) search on the raw data. All quantitative values were normalized against the sum of all precursor intensities from each raw file.

The mass spectrometry proteomics data have been deposited to the ProteomeXchange Consortium via the PRIDE (54) partner repository with the dataset identifier PXD025471 and 10.6019/PXD025471.

\section{Activity tests}

\section{Cofactor activity (CA)}

CA was measured in fluid phase. MFHR13, MFHR1 $1^{162}, \mathrm{MFHR}^{\mathrm{V} 62}$ or $\mathrm{hFH}$ (15 or $75 \mathrm{nM}$ ) were incubated in DPBS with $444 \mathrm{nM} \mathrm{C} 3 \mathrm{~b}$ and $227 \mathrm{nM} \mathrm{FI}$ at $37^{\circ} \mathrm{C}$. Samples $(20 \mu \mathrm{L})$ were collected at different reaction times up to $20 \mathrm{~min}$. The reaction was stopped by the addition of $7.7 \mu \mathrm{L} 4 \mathrm{x}$ 
Laemmli buffer (Bio-Rad) with $3 \mu \mathrm{L} 50 \mathrm{mM}$ DTT (NuPAGE, Thermo Fisher Scientific). Proteolytic cleavage of C3b was assessed by visualizing the $\alpha$-chain cleavage fragments a'68 and a' 43 by SDS-PAGE in $7.5 \%$ gels under reducing conditions followed by Coomassie staining. The bands corresponding to the intact C3b $\alpha^{\prime}$-chain were quantified by densitometry (GelAnalyzer 19.1; www.gelanalyzer.com) and normalized with the corresponding C3b- $\beta$-chain. The ratio $\alpha$ '-chain/ $\beta$-chain at time 0 was set to $100 \%$ intact C3b a'-chain.

\section{Decay acceleration activity assay (DAA)}

The DAA in fluid phase was performed by an ELISA-based method as previously described (37). Briefly, $250 \mathrm{ng} \mathrm{C} 3 \mathrm{~b}$ in PBS were immobilized on Maxisorp plates overnight at $4^{\circ} \mathrm{C}$. In order to generate the C3 convertases (C3bBb), $400 \mathrm{ng}$ Factor B and $25 \mathrm{ng}$ Factor D (CompTech) were incubated with immobilized $\mathrm{C} 3 \mathrm{~b}$ for $2 \mathrm{~h}$ at $37^{\circ} \mathrm{C}$. Increasing concentrations of moss-made regulators and $\mathrm{hFH}$ (CompTech) were added and incubated for $40 \mathrm{~min}$ at $37^{\circ} \mathrm{C}$ to measure their ability to displace preformed $\mathrm{C} 3$ convertases. The $\mathrm{Bb}$ fragments that remain bound to $\mathrm{C} 3 \mathrm{~b}$ were detected by an anti-factor B polyclonal antibody (Merck, Darmstadt, Germany), followed by HRP-conjugated rabbit anti-goat (Dako, Hamburg, Germany). The absorbance of the preformed C3 convertase without regulators was set to $100 \%$ intact $\mathrm{C} 3$ convertases and the $\mathrm{C} 3$ proconvertase $(\mathrm{C} 3 \mathrm{bB})(\mathrm{FB}$ without adding FD) was included as a negative control.

\section{Binding to complement proteins}

The ability of MFHR13 and MFHR1 variants to bind to the complement proteins was tested by ELISA. For this, $5 \mu \mathrm{g} / \mathrm{mL}$ of C3b, C5, C6, C7, C8, C9 or the complex C5b6 (CompTech, USA) in coating buffer were immobilized on Maxisorp plates at $4^{\circ} \mathrm{C}$ overnight, blocked and subsequently incubated with increasing concentrations of MFHR13, MFHR $1^{162}$ or MFHR $1^{\mathrm{V} 62}(0.195-50 \mathrm{nM})$ in the case of testing $\mathrm{C} 3 \mathrm{~b}$ and $\mathrm{C} 5$ binding or a single concentration ( $25 \mathrm{nM}$ or $50 \mathrm{nM})$ in the case of testing $\mathrm{C} 6, \mathrm{C} 7, \mathrm{C} 8, \mathrm{C} 9$ and $\mathrm{C} 5 \mathrm{~b} 6$ binding, diluted in sample buffer. Bound regulators were detected with anti-His-tag antibodies (MAB050, R\&D Systems, 1:1,000 in washing buffer) and HRPconjugated anti-mouse IgG sheep (NA931, Cytiva, 1:5,000 in washing buffer). In order to combine all independent experiments, the absorbance was normalized with the value corresponding to the highest concentration for every binding ELISA to obtain a relative binding.

Recombinant FHR1 with a C-terminal 6x His-tag (Abcam 152006) and hFH (CompTech, USA) were included as controls. However, due to the absence of His-tag in $\mathrm{hFH}$, bound-hFH was detected with a polyclonal antibody (55) (1:1,000 in washing buffer), and the HRP-conjugated anti-rabbit (1:5,000 in washing buffer). It should also be considered, that the affinity of the anti-His-tag antibodies towards FHR1 compared to MFHR13, MFHR1 $1^{162}$ and MFHR $1^{\mathrm{V} 62}$ might be different, due to the different lengths of the His-tags.

\section{Heparin binding}

Heparin-coated microplates (Bioworld, Dublin, Ohio, USA) were used to analyze binding of the regulators to this glycosaminoglycan (GAG) analog. Bound proteins were detected with antiFH $\mathrm{H}_{1-4}$ (1:1,000 in washing buffer) and HRP-conjugated anti-rabbit IgG from donkey (1:2,000 in washing buffer, Cytiva).

\section{Overall AP regulatory activity}

The ELISA-based assay used to analyze the overall ability of the regulators to inhibit TCC formation after activation of the AP with lipopolysaccharides (LPS) was performed as previously described (32) with slight modifications. Briefly, increasing concentrations of MFHR13, MFHR1 ${ }^{162}, M F H R 1^{\mathrm{V} 62}$, eculizumab or $\mathrm{hFH}(0.5-100 \mathrm{nM})$ were tested and formation of C5b-9 complex was detected using a C9 neoepitope-specific antibody (aE11, Santa Cruz Biotechnology, 1:2,000 in DPBS/0.05\% Tween20), followed by HRP-conjugated anti-mouse IgG goat (NXA931, Cytiva; $1: 5,000$ in DPBS/0.05\% Tween-20). Samples with normal human serum (NHS) and without regulators were set to $100 \%$ AP activity. Heat-inactivated NHS $\left(56^{\circ} \mathrm{C}\right.$ for $\left.30 \mathrm{~min}\right)$ was used as a blank. A negative control to indicate spontaneous activation was included, which consisted of NHS without LPS and regulators.

The ability of the regulators to protect sheep erythrocytes from complement-mediated lysis was measured as follows: Increasing concentrations of MFHR13, MFHR1 ${ }^{162}$, MFHR1 ${ }^{\mathrm{V} 62}$, eculizumab or $\mathrm{hFH}(0.3-100 \mathrm{nM})$ were incubated with $5 \times 10^{7}$ sheep erythrocytes followed by the addition of $30 \%$ 
FH-depleted serum (CompTech, USA) prepared in GVB/MgEGTA buffer $(0.1 \%$ gelatin, $5 \mathrm{mM}$ Veronal, $145 \mathrm{mM} \mathrm{NaCl}, 0.025 \% \mathrm{NaN} 3,5 \mathrm{mM} \mathrm{MgCl} 2,5 \mathrm{mM}$ EGTA, pH 7.3). The reaction was incubated for $30 \mathrm{~min}$ at $37^{\circ} \mathrm{C}$ and stopped with GVB/EDTA $(0.1 \%$ gelatin, $5 \mathrm{mM}$ Veronal, $145 \mathrm{mM}$ $\mathrm{NaCl}, 0.025 \% \mathrm{NaN}_{3}, 10 \mathrm{mM}$ EDTA). The amount of hemoglobin released was measured at $405 \mathrm{~nm}$. Samples without regulators were set to $100 \%$ hemolysis, samples lacking NHS were included as negative controls and the values were subtracted from all samples.

\section{Regulation of MAC formation on sheep erythrocytes}

The inhibition of MAC formation on sheep erythrocytes was performed as previously described (10) with modifications. C5b6 (3.5 nM) was incubated with increasing amounts of the protein of interest (MFHR13, MFHR1 ${ }^{162}$, MFHR1 $^{\mathrm{V} 62}, \mathrm{hFH}$, FHR1 (R\&D systems) or eculizumab, $1000 \mathrm{nM}$ ) for 10 minutes. Then a mixture of C7 $(9 \mathrm{nM}), \mathrm{C} 8(0.667 \mathrm{nM}), \mathrm{C} 9(15 \mathrm{nM})$ and $5 \times 10^{7}$ sheep erythrocytes was added (prepared in GVB/ MgEGTA buffer) in $50 \mu \mathrm{L}$ total volume. Hemolysis was detected after 40 minutes at $37^{\circ} \mathrm{C}$ by addition of GVB/EDTA buffer. The amount of hemoglobin released was measured at $405 \mathrm{~nm}$. Samples without regulators were set to 100\% MAC-induced lysis. BSA or purified extract from the parental line $(\Delta x t / f t)$ were included as controls. Two negative controls without C5b6 or C9 were included, which were subtracted from all samples.

\section{Regulation of convertase-independent activation of C5 and MAC formation on sheep erythrocytes}

The ability of the regulators to inhibit convertase-independent activation of $\mathrm{C} 5$ and subsequent MAC formation was tested in a hemolytic assay. For this, C3b-opsonization on erythrocytes was carried out as previously described (56) with some modifications. To achieve maximal C3b deposition without significant MAC formation, FB was partially inactivated in $\mathrm{FH}$-depleted serum at $50^{\circ} \mathrm{C}$ for 5 min and $45 \mu \mathrm{L}$ of this pretreated serum were added to $1 \mathrm{~mL}$ sheep erythrocytes $\left(10^{9} / \mathrm{mL}\right.$ in GVB/EGTA-Mg ${ }^{2+}$ ) and incubated at $37^{\circ} \mathrm{C}$ for $35 \mathrm{~min}$. Cells were washed 4 times with DPBS and resuspended in $1 \mathrm{~mL}$ GVB/EDTA buffer (CompTech) to prevent formation of C3 convertases in case of residual FB.

C5 (75 nM) was preincubated for 15 min with MFHR13, FHR1, hFH or eculizumab (700 nM). BSA, cytochrome c (Sigma 2037), or purified extract from the parental line $(\Delta x t / f t)$ were included as controls. C3b-opsonized erythrocytes $\left(5 \times 10^{7}\right.$ cells) together with $\mathrm{C} 6(110 \mathrm{nM})$ were added to the regulator mix and incubated for $10 \mathrm{~min}$ at $37^{\circ} \mathrm{C}$. Then, C7 (120 nM), C8 (70 nM), C9 (180 nM) were added to a total volume of $50 \mu \mathrm{L}$. After $45 \mathrm{~min}$ at $37^{\circ} \mathrm{C} 100 \mu \mathrm{L} \mathrm{GVB} / \mathrm{EDTA}$ were added and hemolysis was detected by measuring absorbance at $405 \mathrm{~nm}$. Lysis without regulators was set to $100 \%$. The negative control without C5 was subtracted from samples and controls.

\section{Statistical analysis}

Analyses were done with the GraphPad Prism software version 8.0 for Windows (GraphPad software, San Diego, California, USA). For experiments involving a dose-response curve, logarithmic transformed data were fitted by a four-parameter logistic (4PL) nonlinear regression model to calculate the $\mathrm{IC}_{50}$ and comparison of fits was carried out using the extra sum-of-squares $\mathrm{F}$ test with a cutoff at $\mathrm{P}=0.05$.

\section{Acknowledgements}

This work was supported by the Deutscher Akademischer Austauschdienst DAAD (to NRM), the Wissenschaftliche Gesellschaft Freiburg im Breisgau (to NRM) and the Deutsche Forschungsgemeinschaft (DFG, German Research Foundation) under Germany's Excellence Strategy EXC-2189 (CIBSS; to RR). PFZ acknowledges support from KIdnees lowa City USA and from the Deutsche Forschungsgemeinschaft, Collaborative Research Center SFB1192, Immune mediated Glomerular Diseases, project B6. We thank Prof. Dr. Bettina Warscheid for the possibility to use the QExactive Plus instrument, Agnes Novakovic for excellent technical assistance and Anne Katrin Prowse for proof-reading of the manuscript. 


\section{Data availability}

All data generated in this study is included in this paper and the supplementary information. The mass spectrometry proteomics data have been deposited to the ProteomeXchange Consortium via the PRIDE partner repository with the dataset identifier PXD025471 and 10.6019/PXD025471.

\section{References}

1. P. F. Zipfel, C. Skerka, Complement regulators and inhibitory proteins. Nat. Rev. Immunol. 9, 729-740 (2009).

2. D. Ricklin, E. S. Reis, D. C. Mastellos, P. Gros, J. D. Lambris, Complement component C3 The "Swiss Army Knife" of innate immunity and host defense. Immunol. Rev. 274, 33-58 (2016).

3. M. Harboe, G. Ulvund, L. Vien, M. Fung, T. E. Mollnes, The quantitative role of alternative pathway amplification in classical pathway induced terminal complement activation. Clin. Exp. Immunol. 138, 439-446 (2004).

4. K. Fromell, et al., Assessment of the role of $\mathrm{C} 3(\mathrm{H} 2 \mathrm{O})$ in the alternative pathway. Front. Immunol. 11, 530 (2020).

5. M. Mannes, et al., Complement inhibition at the level of C3 or C5: Mechanistic reasons for ongoing terminal pathway activity. Blood 137, 443-455 (2021).

6. J. V. Sarma, P. A. Ward, The complement system. Cell Tissue Res. 343, 227-235 (2011).

7. C. Q. Schmidt, et al., A new map of glycosaminoglycan and C3b binding sites on factor H. J. Immunol. 181, 2610-2619 (2008).

8. P. F. Zipfel, T. Wiech, E. D. Stea, C. Skerka, CFHR gene variations provide insights in the pathogenesis of the kidney diseases atypical hemolytic uremic syndrome and C3 glomerulopathy. J. Am. Soc. Nephrol. 31, 241-256 (2020).

9. A. Haque, et al., Characterization of binding properties of individual functional sites of human complement factor H. Front. Immunol. 11, 1728 (2020).

10. S. Heinen, et al., Factor H-related protein 1 (CFHR-1) inhibits complement C5 convertase activity and terminal complex formation. Blood 114, 2439-2447 (2009).

11. T. Kajander, et al., Dual interaction of factor $\mathrm{H}$ with $\mathrm{C} 3 \mathrm{~d}$ and glycosaminoglycans in hostnonhost discrimination by complement. Proc. Natl. Acad. Sci. U. S. A. 108, 2897-2902 (2011).

12. C. Skerka, et al., Factor H-related protein 1: a complement regulatory protein and guardian of necrotic-type surfaces. Br. J. Pharmacol., bph.15290 (2020).

13. A. M. Risitano, et al., Anti-complement Treatment for Paroxysmal Nocturnal Hemoglobinuria: Time for proximal complement inhibition? A position paper from the SAAWP of the EBMT. Front. Immunol. 10, 1157 (2019).

14. M. Heurich, et al., Common polymorphisms in $\mathrm{C} 3$, factor $\mathrm{B}$, and factor $\mathrm{H}$ collaborate to determine systemic complement activity and disease risk. Proc. Natl. Acad. Sci. U. S. A. 108, 8761-8766 (2011).

15. A. F. Pastor, et al., Complement factor $\mathrm{H}$ gene (CFH) polymorphisms C-257T, G257A and haplotypes are associated with protection against severe dengue phenotype, possible related with high CFH expression. Hum. Immunol. 74, 1225-1230 (2013).

16. A. Tortajada, et al., The disease-protective complement factor $\mathrm{H}$ allotypic variant lle62 shows increased binding affinity for $\mathrm{C} 3 \mathrm{~b}$ and enhanced cofactor activity. Hum. Mol. Genet. 18, 3452-3461 (2009). 
17. D. J. Kittlesen, K. A. Chianese-Bullock, Z. Q. Yao, T. J. Braciale, Y. S. Hahn, Interaction between complement receptor $\mathrm{gC1qR}$ and hepatitis $\mathrm{C}$ virus core protein inhibits $\mathrm{T}$ lymphocyte proliferation. J. Clin. Invest. 106, 1239-1249 (2000).

18. J. M. Carr, S. Cabezas-Falcon, J. G. Dubowsky, J. Hulme-Jones, D. L. Gordon, Dengue virus and the complement alternative pathway. FEBS Lett. 594, 2543-2555 (2020).

19. T. Gao, et al., Highly pathogenic coronavirus N protein aggravates lung injury by MASP-2mediated complement over-activation. medRxiv, 2020.03.29.20041962 (2020).

20. L. E. Gralinski, et al., Complement activation contributes to severe acute respiratory syndrome coronavirus pathogenesis. MBio 9, 1753-1771 (2018).

21. K. S. Aye, et al., Pathologic highlights of dengue hemorrhagic fever in 13 autopsy cases from Myanmar. Hum. Pathol. 45, 1221-1233 (2014).

22. L. Ma, et al., Increased complement activation is a distinctive feature of severe SARS-CoV-2 infection. bioRxiv, 2021.02.22.432177 (2021).

23. D. C. Mastellos, et al., Complement C3 vs C5 inhibition in severe COVID-19: Early clinical findings reveal differential biological efficacy. Clin. Immunol. 220, 108598 (2020).

24. A. M. Risitano, et al., Complement as a target in COVID-19? Nat. Rev. Immunol. 20, 343344 (2020).

25. P. Urwyler, et al., Treatment of COVID-19 with Conestat Alfa, a regulator of the complement, contact activation and Kallikrein-Kinin system. Front. Immunol. 11, 2072 (2020).

26. A. C. McEneny-King, J. P. R. Monteleone, S. D. Kazani, S. R. Ortiz, Pharmacokinetic and Pharmacodynamic Evaluation of Ravulizumab in Adults with Severe Coronavirus Disease 2019. Infect. Dis. Ther., 1-10 (2021).

27. A. P. J. Vlaar, et al., Anti-C5a antibody IFX-1 (vilobelimab) treatment versus best supportive care for patients with severe COVID-19 (PANAMO): an exploratory, open-label, phase 2 randomised controlled trial. Lancet Rheumatol. 2, e764-e773 (2020).

28. J. Yu, et al., Direct activation of the alternative complement pathway by SARS-CoV-2 spike proteins is blocked by factor D Inhibition. Blood 136, 2080-2089 (2020).

29. W. M. Zelek, L. Xie, B. P. Morgan, C. L. Harris, Compendium of current complement therapeutics. Mol. Immunol. 114, 341-352 (2019).

30. P. F. Zipfel, et al., Complement inhibitors in clinical trials for glomerular diseases. Front. Immunol. 10, 2166 (2019).

31. J. Castañeda-Sanabria, D. Hajage, M. Le Jouan, A. Perozziello, F. Tubach, Off-label use of the expensive orphan drug eculizumab in France 2009-2013 and the impact of literature: Focus on the transplantation field. Eur. J. Clin. Pharmacol. 72, 737-746 (2016).

32. S. Michelfelder, et al., The MFHR1 fusion protein is a novel synthetic multitarget complement inhibitor with therapeutic potential. J. Am. Soc. Nephrol. 29, 1141-1153 (2018).

33. Y. Yang, et al., An engineered complement factor $\mathrm{H}$ construct for treatment of $\mathrm{C} 3$ glomerulopathy. J. Am. Soc. Nephrol. 29, 1649-1661 (2018).

34. M. Fridkis-Hareli, et al., Design and development of TT30, a novel C3d-targeted C3/C5 convertase inhibitor for treatment of human complement alternative pathway-mediated diseases. Blood 118, 4705-4713 (2011).

35. J. B. Hennermann, et al., Pharmacokinetics, pharmacodynamics, and safety of mossaGalactosidase A in patients with Fabry disease. J. Inherit. Metab. Dis. 42, 527-533 (2019).

36. A. Büttner-Mainik, et al., Production of biologically active recombinant human factor $\mathrm{H}$ in Physcomitrella. Plant Biotechnol. J. 9, 373-383 (2011).

37. S. Michelfelder, et al., Moss-produced, glycosylation-optimized human Factor $\mathrm{H}$ for 
therapeutic application in complement disorders. J. Am. Soc. Nephrol. 28, 1462-1474 (2017).

38. O. Top, et al., Recombinant production of MFHR1, a novel synthetic multitarget complement inhibitor, in moss bioreactors. Front. Plant Sci. 10, 260 (2019).

39. S. Hintze, et al., Moss-derived human recombinant GAA provides an optimized enzyme uptake in differentiated human muscle cells of pompe disease. Int. J. Mol. Sci. 21, 2642 (2020).

40. E. L. Decker, R. Reski, Mosses in biotechnology. Curr. Opin. Biotechnol. 61, 21-27 (2020).

41. N. Lingg, P. Zhang, Z. Song, M. Bardor, The sweet tooth of biopharmaceuticals: Importance of recombinant protein glycosylation analysis. Biotechnol. J. 7, 1462-1472 (2012).

42. A. Fiser, A. Šali, MODELLER: Generation and refinement of homology-based protein structure models. Methods Enzymol. 374, 461-491 (2003).

43. R. A. Laskowski, M. W. MacArthur, D. S. Moss, J. M. Thornton, PROCHECK: a program to check the stereochemical quality of protein structures. J. Appl. Crystallogr. 26, 283-291 (1993).

44. M. Wiederstein, M. J. Sippl, ProSA-web: Interactive web service for the recognition of errors in three-dimensional structures of proteins. Nucleic Acids Res. 35, 407-410 (2007).

45. A. Weise, et al., Use of Physcomitrella patens actin 5 ' regions for high transgene expression: Importance of 5' introns. Appl. Microbiol. Biotechnol. 70, 337-345 (2006).

46. A. Schaaf, et al., Use of endogenous signal sequences for transient production and efficient secretion by moss (Physcomitrella patens) cells. BMC Biotechnol. 5, 30 (2005).

47. E. L. Decker, G. Wiedemann, R. Reski, Gene targeting for precision glyco-engineering: Production of biopharmaceuticals devoid of plant-typical glycosylation in moss bioreactors. Methods Mol. Biol. 1321, 213-224 (2015).

48. D. G. Gibson, et al., Enzymatic assembly of DNA molecules up to several hundred kilobases. Nat. Methods 6, 343-345 (2009).

49. N. A. Horst, et al., A single homeobox gene triggers phase transition, embryogenesis and asexual reproduction. Nat. Plants 2, 1520 (2016).

50. A. Koprivova, et al., Targeted knockouts of Physcomitrella lacking plant-specific immunogenic N-glycans. Plant Biotechnol. J. 2, 517-523 (2004).

51. S. Kühn, C. Skerka, P. F. Zipfel, Mapping of the complement regulatory domains in the human factor H-like protein 1 and in factor H1. J. Immunol. 155, 5663-5670 (1995).

52. L. L. Bohlender, et al., Stable protein sialylation in Physcomitrella. Front. Plant Sci. 11, 2078 (2020).

53. D. Lang, et al., The Physcomitrella patens chromosome-scale assembly reveals moss genome structure and evolution. Plant J. 93, 515-533 (2018).

54. Y. Perez-Riverol, et al., The PRIDE database and related tools and resources in 2019: Improving support for quantification data. Nucleic Acids Res. 47, 442-450 (2019).

55. M. Oppermann, et al., The C-terminus of complement regulator Factor $\mathrm{H}$ mediates target recognition: Evidence for a compact conformation of the native protein. Clin. Exp. Immunol. 144, 342-352 (2006).

56. Y. Zhang, et al., Causes of alternative pathway dysregulation in dense deposit disease. Clin. J. Am. Soc. Nephrol. 7, 265-274 (2012).

57. C. Q. Schmidt, et al., Rational engineering of a minimized immune inhibitor with unique triple-targeting properties. J. Immunol. 190, 5712-5721 (2013). 
58. F. Fenaille, et al., Site-specific N-glycan characterization of human complement factor $\mathrm{H}$. Glycobiology 17, 932-944 (2007).

59. K. Kaartinen, A. Safa, S. Kotha, G. Ratti, S. Meri, Complement dysregulation in glomerulonephritis. Semin. Immunol. 45, 101331 (2019).

60. M. C. Pickering, et al., Spontaneous hemolytic uremic syndrome triggered by complement factor $\mathrm{H}$ lacking surface recognition domains. J. Exp. Med. 204, 1249-1256 (2007).

61. $\mathrm{H}$. G. Hocking, et al., Structure of the N-terminal region of complement factor $\mathrm{H}$ and conformational implications of disease-linked sequence variations. J. Biol. Chem. 283, 9475-9487 (2008).

62. E. Tsuda, G. Kawanishi, M. Ueda, S. Masuda, R. Sasaki, The role of carbohydrate in recombinant human erythropoietin. Eur. J. Biochem. 188, 405-411 (1990).

63. A. I. Okemefuna, R. Nan, J. Gor, S. J. Perkins, Electrostatic interactions contribute to the folded-back conformation of wild type human factor H. J. Mol. Biol. 391, 98-118 (2009).

64. J. Parsons, et al., Moss-based production of asialo-erythropoietin devoid of Lewis $A$ and other plant-typical carbohydrate determinants. Plant Biotechnol. J. 10, 851-861 (2012).

65. F. Higel, et al., N-glycans of complex glycosylated biopharmaceuticals and their impact on protein clearance. Eur. J. Pharm. Biopharm. 139, 123-131 (2019).

66. L. Milis, C. A. Morris, M. C. Sheehan, J. A. Charlesworth, B. A. Pussel, Vitronectin-mediated inhibition of complement: evidence for different binding sites for C5b-7 and C9. Clin. Exp. Immunol. 92, 114-119 (1993).

67. E. G. de Jorge, et al., Dimerization of complement factor H-related proteins modulates complement activation in vivo. Proc. Natl. Acad. Sci. U. S. A. 110, 4685-4690 (2013).

68. M. Cserhalmi, A. Papp, B. Brandus, B. Uzonyi, M. Józsi, Regulation of regulators: Role of the complement factor H-related proteins. Semin. Immunol. 45, 101341 (2019).

69. G. Sun, H. Li, Y. Wang, B. Zhang, S. Zhang, Zebrafish complement factor $\mathrm{H}$ and its related genes: Identification, evolution, and expression. Funct. Integr. Genomics 10, 577-587 (2010).

70. X. Li, Z. Hao, X. Liu, W. Li, Deficiency of mouse FHR-1 homolog, FHR-E, accelerates sepsis, and acute kidney injury through enhancing the LPS-induced alternative complement pathway. Front. Immunol. 11, 1123 (2020). 
a

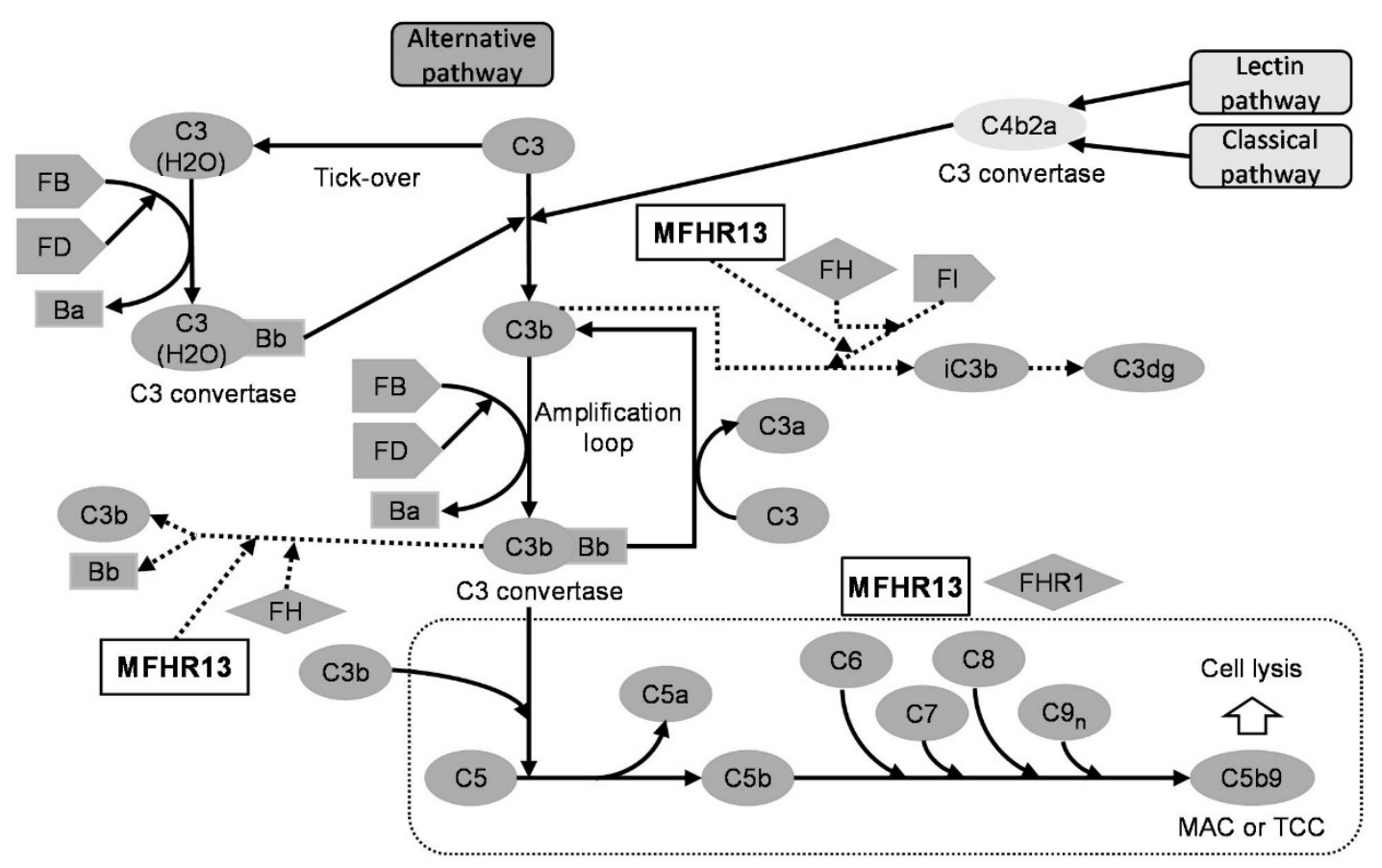

b

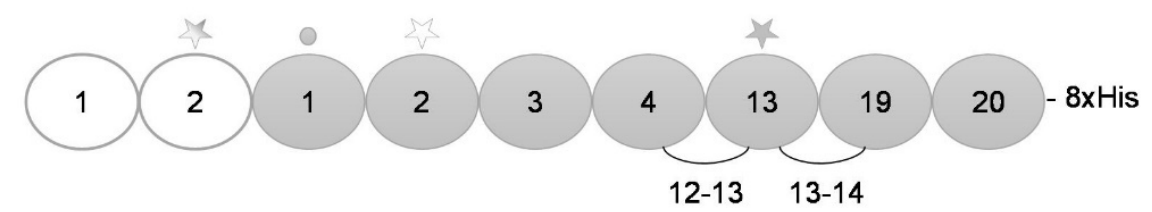

Figure 1. Schematic representation of complement activation and amplification by the alternative pathway (AP) and the mechanism of action of MFHR13. (a) MFHR13 is a regulator of the AP activation at the level of $\mathrm{C} 3$ and C5. The complement is activated by three pathways which converge in the formation of C3 convertases and lead to the assembly of C5b-9, called membrane attack complex (MAC), able to induce lysis and cell death. The AP is activated by spontaneous hydrolysis of C3 and acts as an amplification loop for the cleavage of C3, even when complement was activated by the classical or lectin pathways. Dotted lines and box represent sites of downregulation of AP including the sites where MFHR13 act as regulator in the cascade. (b) MFHR13 consists of SCRs FHR1 $1_{1-2}$ (white) and 7 SCRs of FH (gray) fused by natural linkers. The gray and white stars indicate glycosylation sites and a deamidated glycosylation site, respectively. The gray dot indicates the position of the polymorphism V62I. 
a

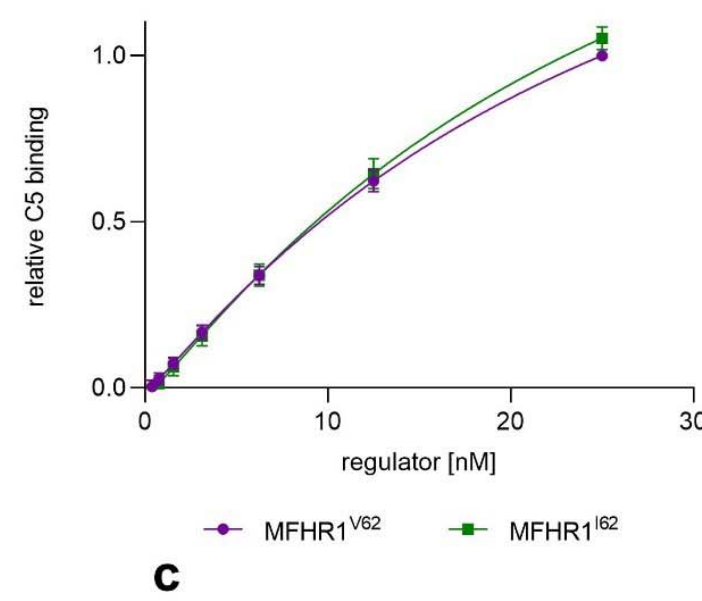

b

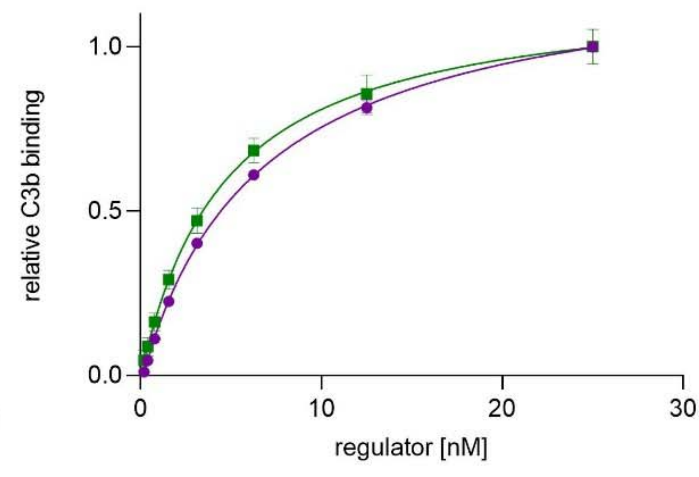

$\rightarrow \mathrm{MFHR}^{\mathrm{V} 62} \rightarrow \mathrm{MFHR}^{162}$

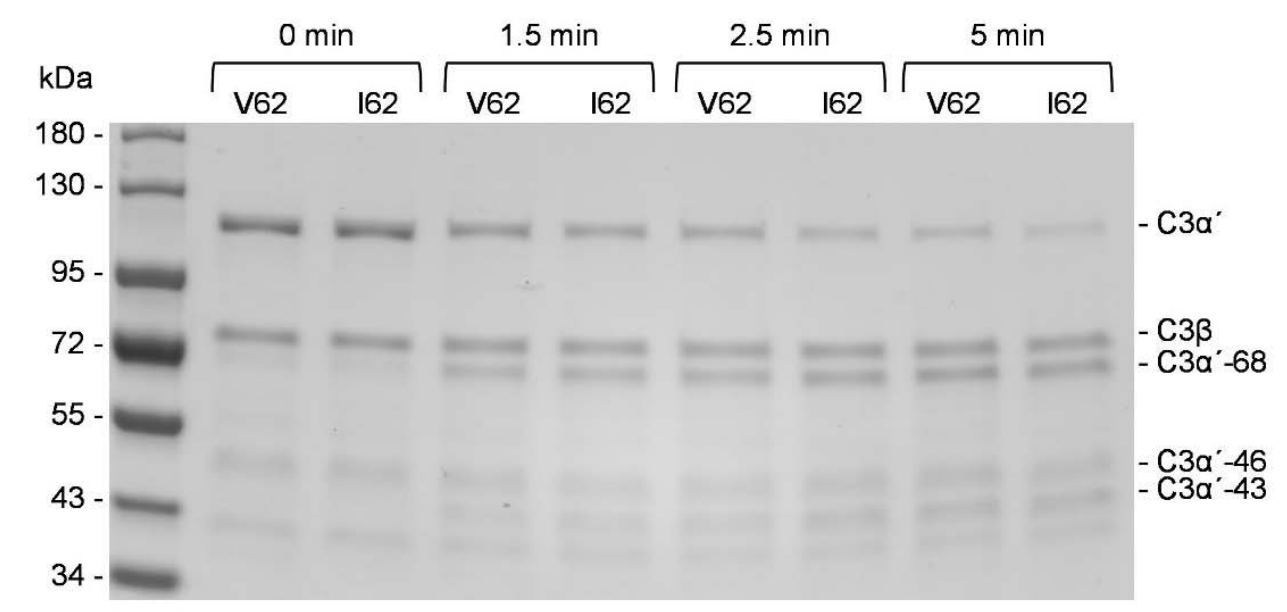

\section{d}

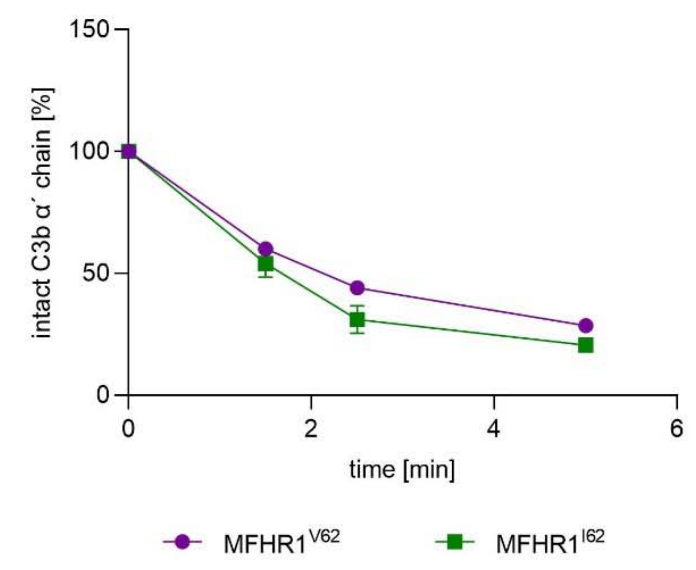

e

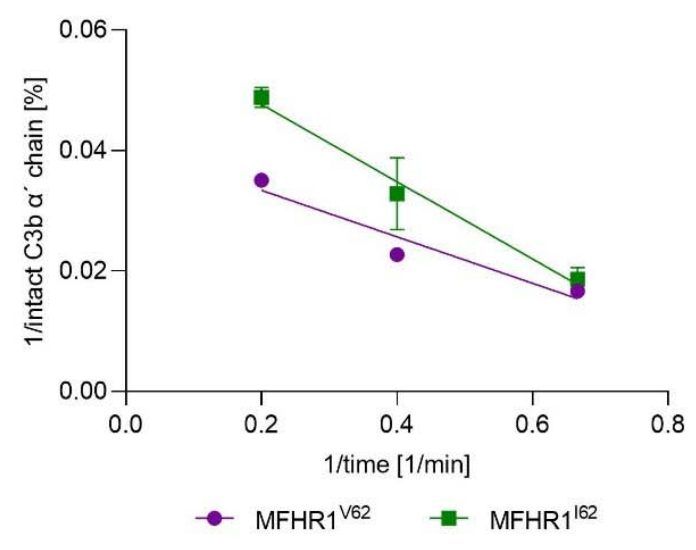

Figure 2. MFHR1 ${ }^{162}$ displays better C3b binding and cofactor activity than MFHR1 ${ }^{\mathrm{V} 62}$. (a) Binding to immobilized C5 was evaluated by ELISA with increasing concentrations of MFHR1 $1^{162^{\circ}}$ and 
MFHR $1^{\mathrm{V} 62}$. Nonlinear regression using the sigmoidal equation and logarithmic transformed data showed no significant differences between both variants binding to $C 5(P=0.9328)$. Data represent mean values \pm SD from 3 independent experiments. (b) Binding to immobilized C3b was evaluated by ELISA with increasing concentrations of MFHR1 $1^{162}$ and MFHR1 $1^{\mathrm{V} 62}$. Nonlinear regression using the sigmoidal equation (dose response curve, 4 parameters) showed significant differences between both variants binding to $\mathrm{C} 3 \mathrm{~b}(\mathrm{P}=0.0437)$. (c) Cofactor activity of FI-mediated proteolytic cleavage of C3b $\alpha^{\prime}$-chain in the presence of MFHR $1^{162}$ or MFHR1 $1^{\mathrm{V} 62}$ was visualized by SDS-PAGE and Coomassie staining. One representative experiment is shown. (d) Densitometric analysis of C3b cleavage. The amount of intact $\alpha^{\prime}$-chain was normalized for each sample with the $\beta$-chain and set to $100 \%$ intact C3b a'-chain at time zero. Two independent experiments were included in the analysis. (e) Double reciprocal plot of the percentage of intact C3b $\alpha^{\prime}$-chain. Linear regression analysis indicated significant differences between the MFHR1 variants $(P=0.0302)$. 
a

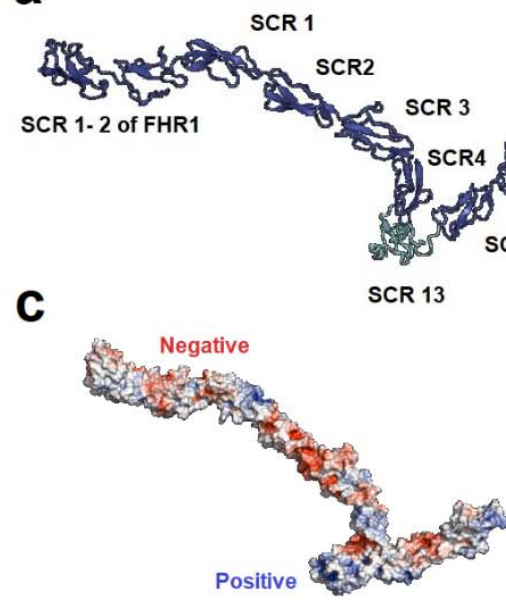

b

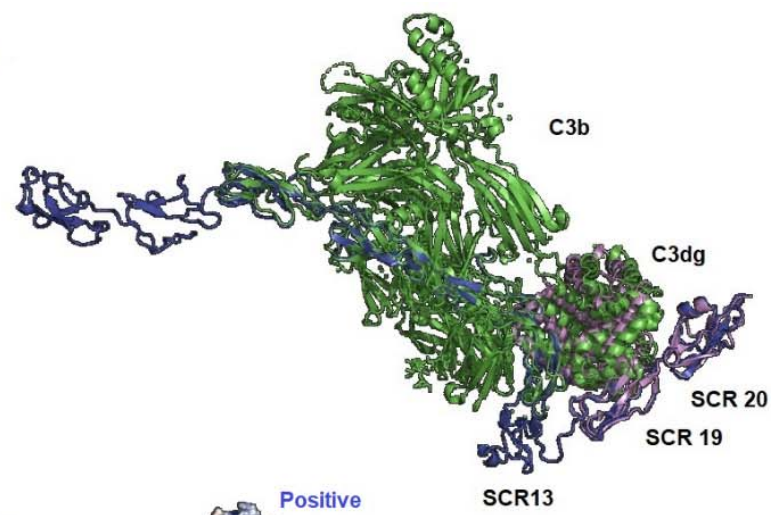

Figure 3. Comparative protein structure modelling of the fusion protein MFHR13 (FHR1 2: $\mathrm{FH}_{1-4}: \mathrm{FH}_{13}: \mathrm{FH}_{19-20}$ ). (a) Model of MFHR13 built in Modeller 9.19. (b) Superimposition of the model MFHR13 (blue) with C3b (green) and C3dg (purple), respectively. Root-mean-square deviation of atomic positions (RMS) between the structure C3b: $\mathrm{FH}_{1-4}$ (PDB 2WII) and modelled MFHR13 is 1.345. (c) Electrostatic potential of MFHR13. Electronegative residues are displayed in red, electropositive in blue. The electropositive patch extending over one face of $\mathrm{FH}_{13}$ to $\mathrm{FH}_{20}$ is on the right-hand side. The electrostatic potential was determined using Adaptive Poisson-Boltzmann Solver included in PyMOL 2.0. 
a

C

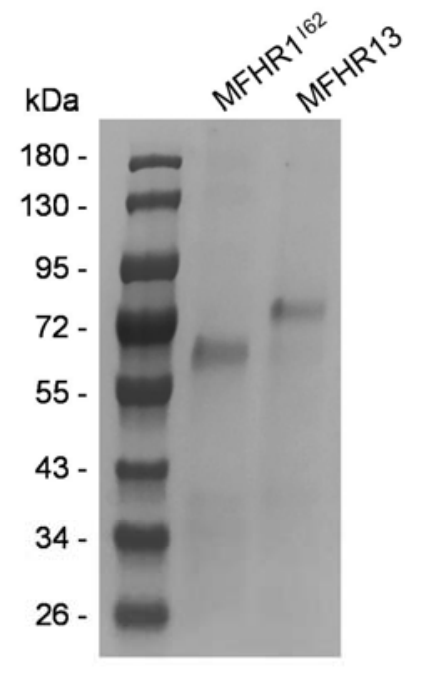

b

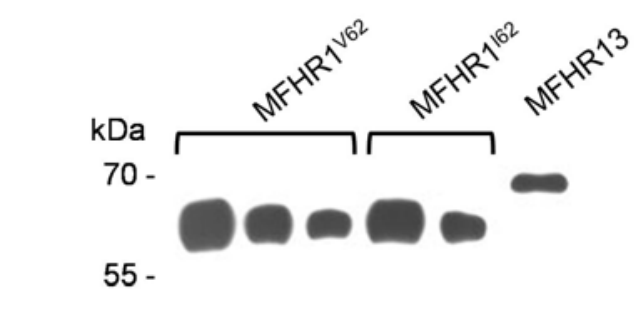

34 -

Regulator 70035017550025070 (ng)

1 MGASRSVRLAFFLVLVLAALAEAEATFCDFPKINHGILYDEEKYKPFSQVPTGEVFYY

61 SCEYNFVSPSKSFWTRITCTEEGWSPTPKCLRLCFFPFVENGHSESSGQTHLEGDTVQII

121 CNTGYRLQNNENNISCVERGWSTPPKCRSEDCNELPPRRNTEILTGSWSDQTYPEGTQAI

181 YKCRPGYRSLGNIMVCRKGEWVALNPLRKCQKRPCGHPGDTPFGTFTLTGGNVFEYGVK

241 AVYTCNEGYQLLGEINYRECDTDGWTNDIPICEVVKCLPVTAPENGKIVSSAMEPDREYH

301 FGQAVRFVCNSGYKIEGDEEMHCSDDGFWSKEKPKCVEISCKSPDVINGSPISQKIIYKE

361 NERFQYKCNMGYEYSERGDAVCTESGWRPLPSCEVAIDKLKKCKSSNLIILEEHLKNKKE

421 FDHNSNIRYRCRGKEGWIHTVCINGRWDPEVNCSMAQIQLCGPPPPIDNGDITSFPLSVY

481 APASSVEYQCQNLYQLEGNKRITCRNGQWSEPPKCLHPCVISREIMENYNIALRWTAKQK

541 LYSRTGESVEFVCKRGYRLSSRSHTLRTTCWDGKLEYPTCAKRVDHHHHHHHH

d

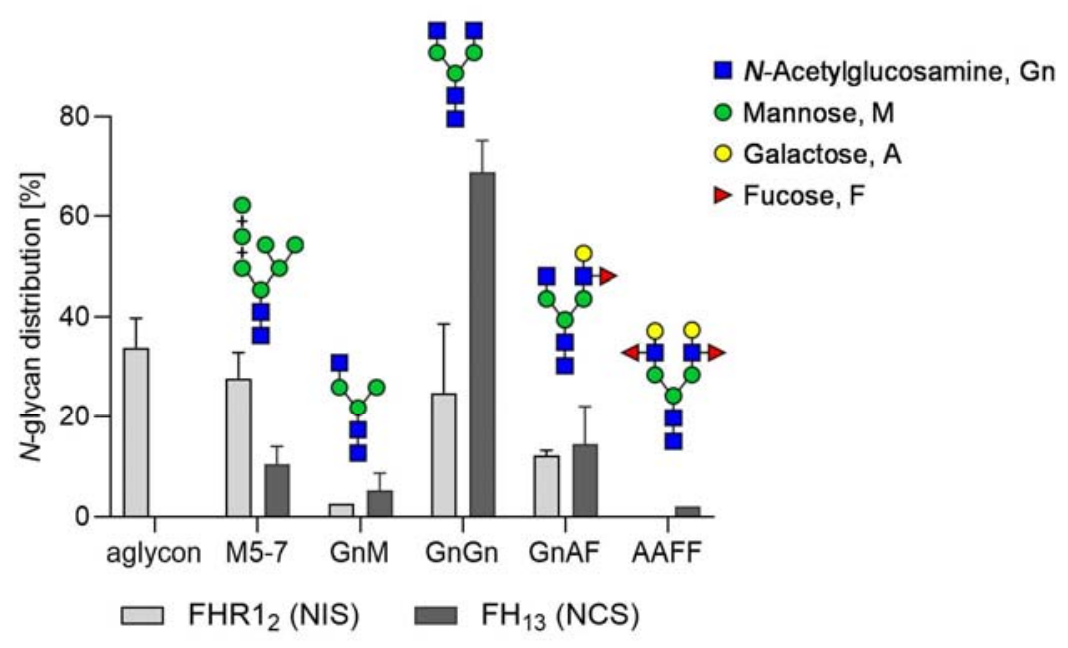


Figure 4. MFHR13 structure and sequence characterization. (a) Coomassie staining of purified MFHR1 $1^{162}$ and MFHR13 via Ni-affinity and anion exchange chromatography. Samples were separated on SDS-PAGE under reducing conditions. (b) Semi-quantitative Western blot of MFHR1 ${ }^{\mathrm{V} 62}$, MFHR1 $1^{162}$ and MFHR13 under reducing conditions and detected with anti-His-tag antibodies. A calibration curve was obtained with MFHR1 ${ }^{\mathrm{V} 62}$ and densities of the Western blot signal were compared with the concentrations obtained by ELISA (included under each lane). One representative experiment is shown. (c) MFHR13 sequence. $F H R 1_{1-2}$ are shown in green, $\mathrm{FH}_{1-4}$, $\mathrm{FH}_{13}, \mathrm{FH}_{19-20}$ are shown in blue, gray and light red, respectively, and the linkers are shown in light yellow. The glycosylation sites are highlighted in red and the deamidated site in italics. The peptides identified by MS are shown in bold. (d) Relative quantification of glycopeptides based on MS. MFHR13 was produced in stirred tank bioreactor $(5 \mathrm{~L})$ and extracted at day 8. NIS: glycosylation site in the FHR1 $1_{2}$ in MFHR13. NCS: glycosylation site in the $\mathrm{FH}_{13}$ in MFHR13. Mean values from two technical replicates with standard deviation are shown. 
a

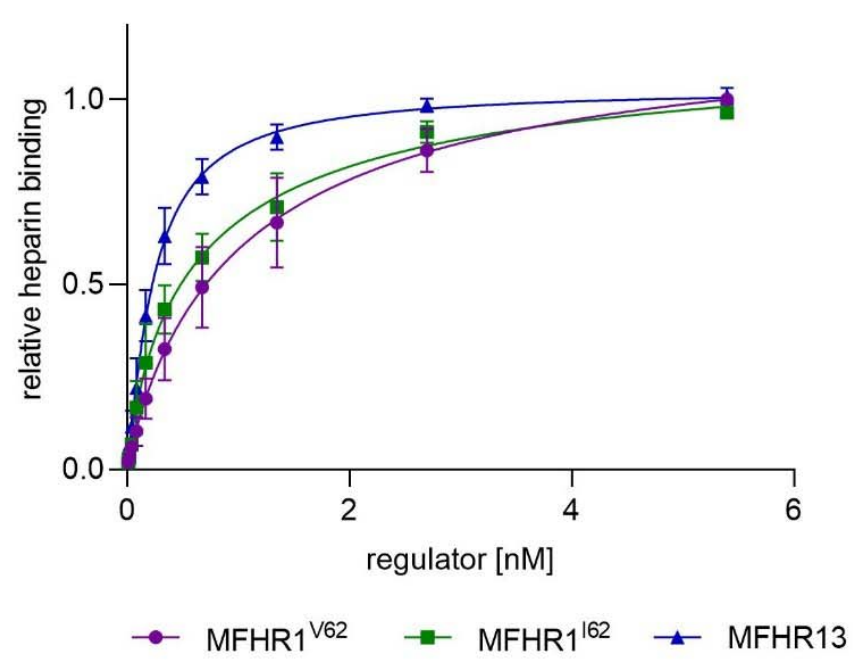

b

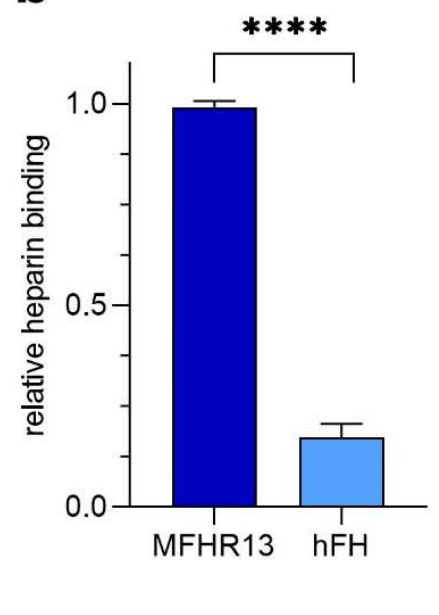

Figure 5. MFHR13 binds better to heparin than MFHR1 ${ }^{162}$, MFHR1 ${ }^{\mathrm{V} 62}$ or hFH. (a) Heparinbinding was measured by ELISA. Nonlinear regression using the sigmoidal equation (dose response curve, 4 parameters) and comparison of $\mathrm{IC}_{50}$ showed significant differences between MFHR13, MFHR1 $1^{162}$ and MFHR1 ${ }^{\mathrm{V} 62}$ binding to heparin $(\mathrm{P}<0.0001$ both comparisons). Data represent mean values \pm SD from 4 independent experiments. The blank (BSA $2 \%$ ) was subtracted from all the samples. (b) MFHR13 binds significantly better to heparin than $h F H \quad(P<0.0001$, unpaired t-test). The binding was measured by ELISA using $25 \mathrm{nM}$ of hFH or MFHR13, respectively. 

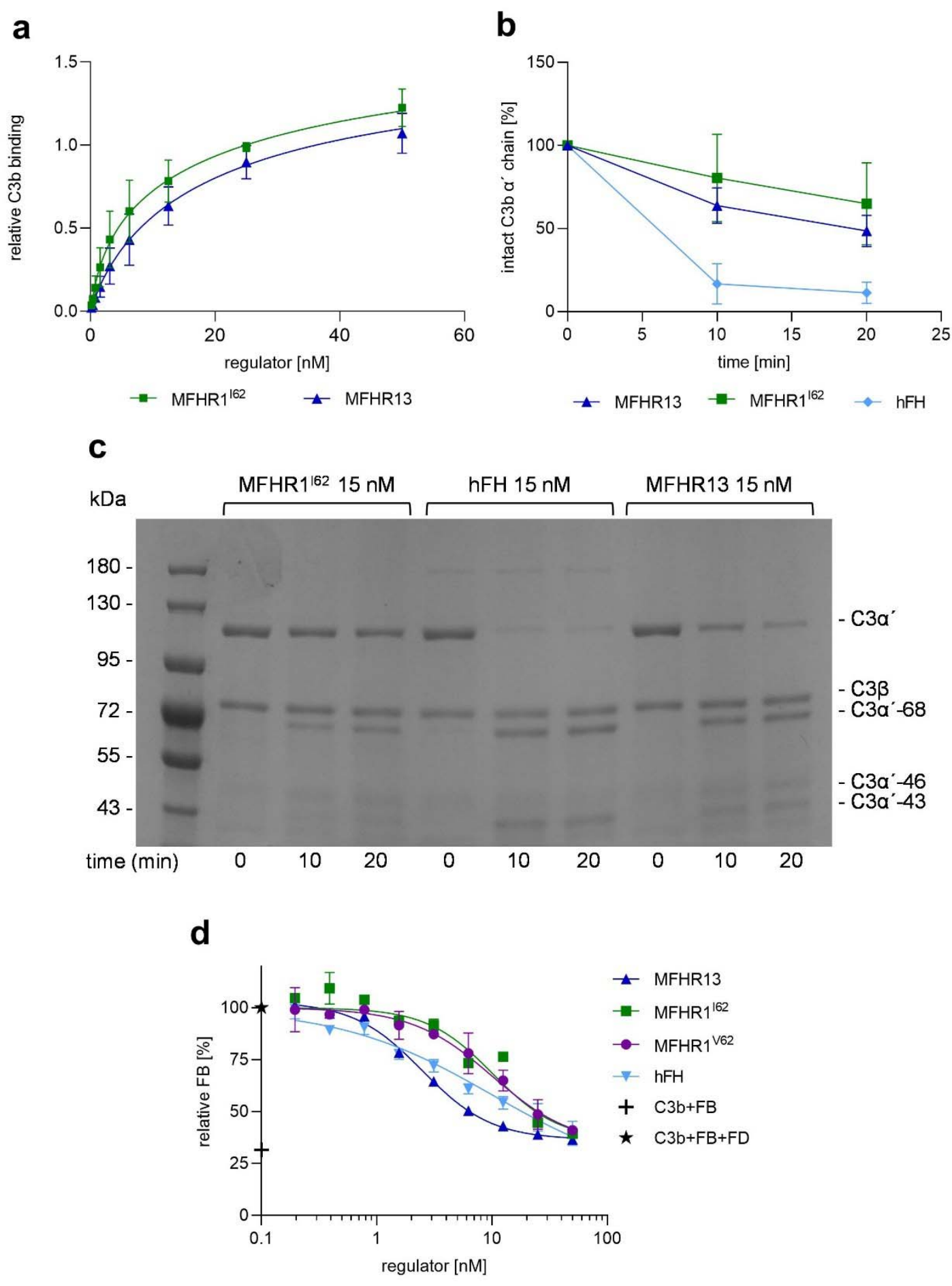

Figure 6. MFHR13 binds to $\mathrm{C} 3 \mathrm{~b}$ and exhibits cofactor and decay acceleration activities in fluid-phase. (a) Nonlinear regression using the sigmoidal equation (dose response curve, 4 parameters) and comparison of $\mathrm{IC}_{50}$ showed no significant differences between MFHR13 and $M F H R^{162}$ binding to $\mathrm{C} 3 \mathrm{~b}(\mathrm{P}=0.8426)$. Data represent mean values $\pm \mathrm{SD}$ from 5 independent experiments. (b) Cofactor activity of $\mathrm{Fl}$-mediated proteolytic cleavage of $\mathrm{C} 3 \mathrm{~b}$ a'-chain in the presence of MFHR1 $1^{162}, \mathrm{FH}$ or MFHR13, evaluated in increasing reaction times. Densitometric analysis of $\mathrm{C} 3 \mathrm{~b}$ cleavage. The amount of intact $\alpha^{\prime}$-chain was normalized for each sample with the 
$\beta$-chain and set to $100 \%$ intact C3b a'-chain at time zero. The data represent mean value from 5 or 6 independent experiments \pm SD. (c) One representative experiment included in $b$ is shown. C3b, $\mathrm{FI}$, and MFHR $1^{162}$, MFHR13 or FH were incubated for 10 and $20 \mathrm{~min}$ and $\mathrm{C} 3 \mathrm{~b}$ cleavage was visualized by SDS-PAGE and Coomassie staining. (d) MFHR13 displaced C3 convertases more efficiently than MFHR1 $1^{162}$ and MFHR $1^{\mathrm{V} 62}$. C3bBb were assembled in C3b-coated microtiter plates with FB and FD. Complement regulators were added and the dissociation of the C3 convertases was detected by the amount of FB using polyclonal anti-FB antibodies. Absorbance of samples without regulator was set to $100 \%$ FB and samples without FD as the negative control. Nonlinear regression using the sigmoidal equation and comparison of $\mathrm{IC}_{50}$ indicated significant differences in DAA between MFHR13, MFHR1 ${ }^{\mathrm{V} 62}$, and MFHR1 $1^{162}(\mathrm{P}<0.0001$ for each comparison) and not significant difference between MFHR13 and hFH $(P=0.2022)$. The data represent mean value from 2 independent measurements \pm SD. 
a

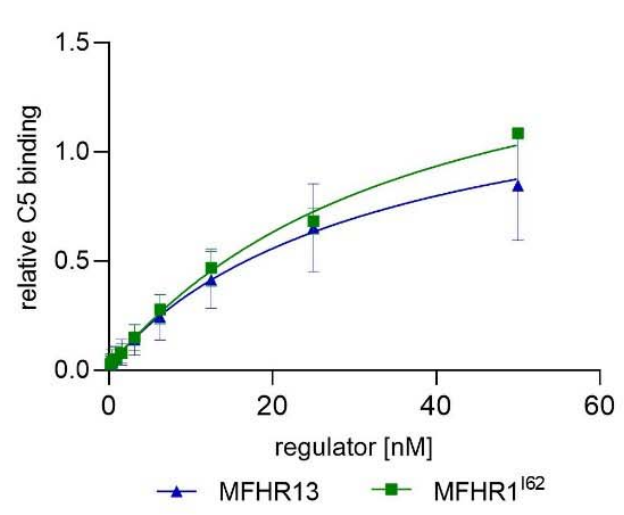

C
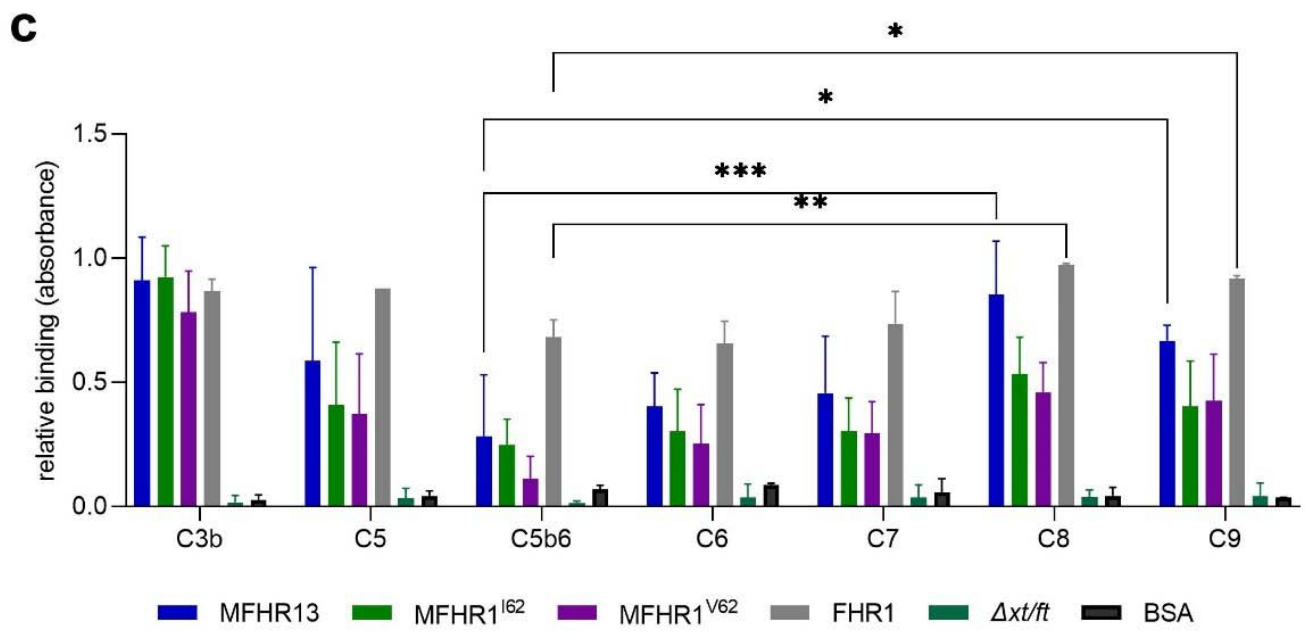

d

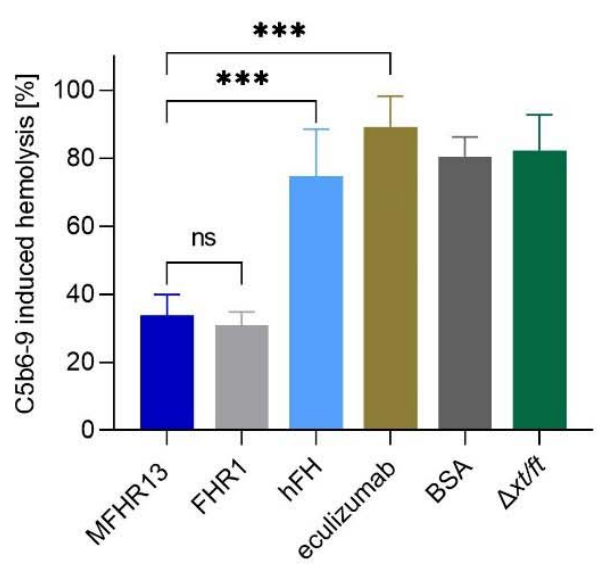

b

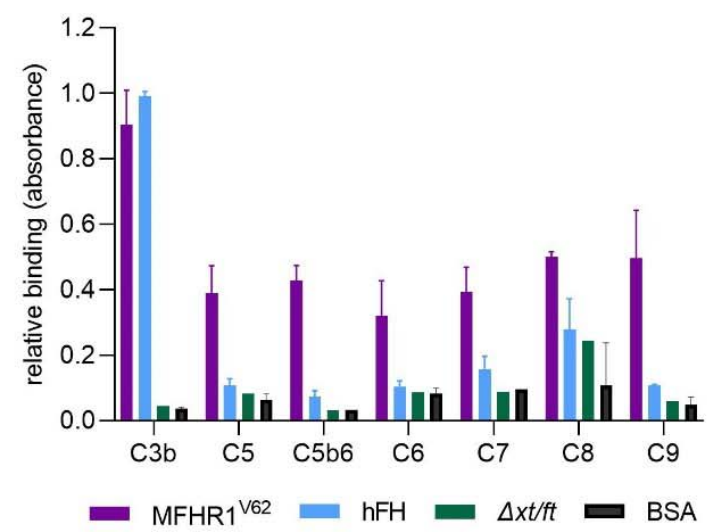

*

e

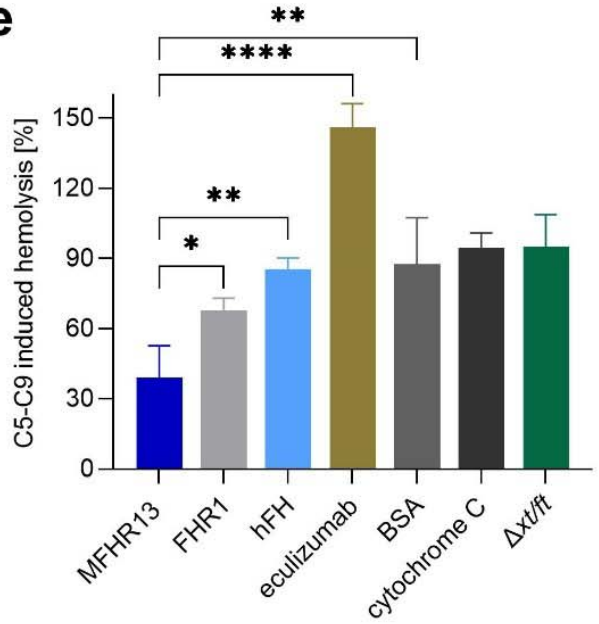

Figure 7. MFHR13 binds $\mathrm{C} 5$ and other MAC components and blocks the terminal pathway. (a) C5 binding was measured by ELISA. Nonlinear regression using the sigmoidal equation and comparison of $\mathrm{IC}_{50}$ showed no significant differences between MFHR1 ${ }^{162}$ and MFHR13 binding to C5 $(P=0.2565)$. Data represent mean values \pm SD from 4 or 5 independent experiments. (b) MFHR1 binds to the proteins involved in the MAC formation but hFH does not. MFHR1 or hFH 
$(25 \mathrm{nM})$ as well as the negative controls BSA and the purified extract from the parental line $(\Delta x t / f t)$ were added to immobilized complement proteins in microtiter plates and detected by anti-FH polyclonal antibodies. Data represent mean values \pm SD from 3 independent experiments. (c) MFHR13, MFHR1 and FHR1 bind to the proteins involved in MAC formation. Regulators (25 nM) were added to immobilized complement proteins and detected by anti-His-tag antibodies. Data represent mean values \pm SD from 3 or 4 independent experiments. FHR1 binds significantly better to $C 8$ and $C 9$ than to $C 5 b 6(P=0.0028$ and $P=0.0245$ respectively, one-way ANOVA, Dunnett's post hoc test). (d) MFHR13 and FHR1 inhibit the formation of the MAC on sheep erythrocytes significantly better than hFH $(P=0.0018)$, eculizumab $(P<0.0001)$, BSA $(P=0.0012)$, or $\Delta x t / f t$. Hemolysis of sheep erythrocytes was induced with C5b6, C7, C8, and C9 and determined by absorbance of released hemoglobin at $405 \mathrm{~nm}$. Lysis without regulators was set to $100 \%$. The average value of the negative controls without $\mathrm{C} 5 \mathrm{~b} 6$, and without $\mathrm{C} 9$ were subtracted from the positive control and samples. Data represent mean values \pm SD from 3 independent experiments. (One-way ANOVA, Bonferroni post hoc test) (e) MFHR13 (700 nM) inhibit the formation of the MAC on C3b-opsonized sheep erythrocytes significantly better than FHR1 $(P=0.0415), h F H(P=0.0018)$, eculizumab $(\mathrm{P}<0.0001)$, BSA $(\mathrm{P}=0.0012)$, and $\Delta x t / f t$. Hemolysis of $\mathrm{C} 3 \mathrm{~b}$-coated sheep erythrocytes was induced with a mix of $\mathrm{C} 5-\mathrm{C} 9$ and determined by absorbance of released hemoglobin at 405 $\mathrm{nm}$. Lysis without regulators was set to $100 \%$. The negative control without C5 was subtracted from the positive control and samples. Data represent mean values \pm SD from 3 independent experiments. (One-way ANOVA, Bonferroni post hoc test). ${ }^{* * *}$ represents $\mathrm{P} \leq 0.0001$, ${ }^{\star * *} \mathrm{P} \leq$ $0.001,{ }^{* *} P \leq 0.01$ and ${ }^{*}$ represents $P \leq 0.05$, ns (no significant difference). 
a

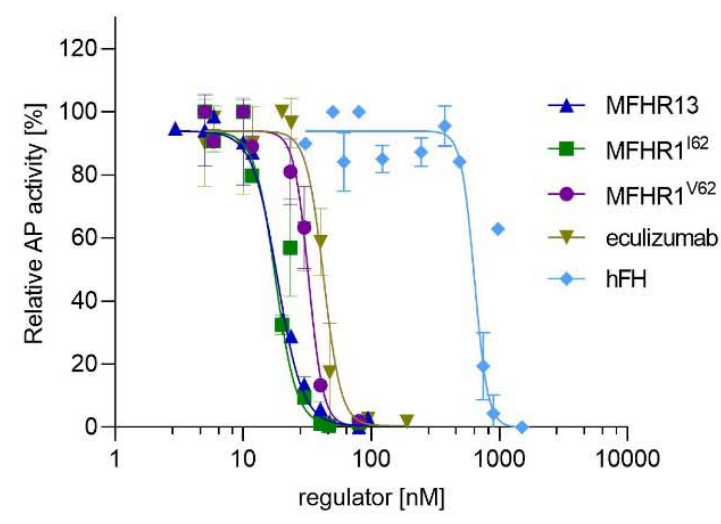

b

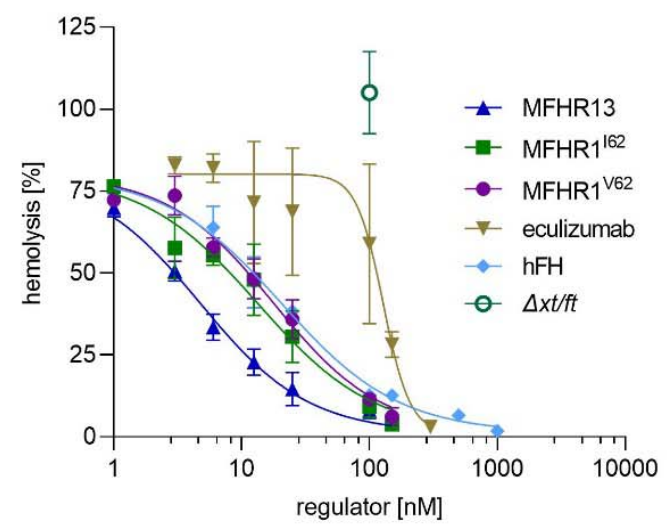

Figure 8. MFHR13 regulates overall AP activation and protects host-like surfaces. (a) Regulation of AP activation. AP in normal human serum was activated in LPS coated wells. The inhibition achieved by addition of regulators was evaluated indirectly by quantifying C5b-9 complex formation by an ELISA based-method. AP activity was set to $100 \%$ for wells without regulators and wells with heat inactivated serum were used as blank. Spontaneous activation was $42 \pm 2.8 \%$, measured in wells without LPS. Data represent mean values \pm SD from 4 independent measurements. MFHR13 regulatory activity was significantly better than $h F H(P<0.0001, F(D F n$, $D F d)=268.5(1,34))$, and eculizumab $(P<0.0001, F(D F n, D F d)=83.38(1,25))$. (b) Increasing concentrations of MFHR13 protected sheep erythrocytes from human complement attack in FHdepleted serum significantly better than MFHR1 ${ }^{162}(P=0.0003, F(D F n, D f d)=16.02(1,36))$, MFHR1 ${ }^{\mathrm{V} 62}(\mathrm{P}<0.0001, \mathrm{~F}(\mathrm{DFn}, \mathrm{Dfd})=54.99(1,42))$, hFH $\left.(\mathrm{P}=0.0001, \mathrm{~F}(\mathrm{DFn}, \mathrm{DFd}))=18.73(1,31)\right)$ and eculizumab $(P<0.0001 F(D F n, D F d))=111.7(1,33))$. Hemolysis was set to $100 \%$ for wells without complement regulators and the negative control without $\mathrm{FH}$-depleted serum was used as blank. Data represent mean values \pm SD from 4 independent measurements. $\Delta x t / f t$ is a purified extract from the parental moss line used as negative control. DF: degrees of freedom 
Table 1. Overall AP regulatory activity evaluated by hemolysis and an ELISA based-method: Best fit $\mathrm{IC}_{50}$ calculated by $4 \mathrm{PL}$ nonlinear regression model. $\mathrm{Cl}$ : Confidence Interval, $\mathrm{R}^{2}$ : Goodness of Fit.

\begin{tabular}{|c|c|c|c|c|c|}
\hline Assay & MFHR13 & MFHR1 $1^{162}$ & MFHR1 $1^{\text {V62 }}$ & hFH & Eculizumab \\
\hline \multicolumn{6}{|c|}{ AP ELISA } \\
\hline $\mathrm{IC}_{50}(\mathrm{nM})$ & 17.8 & 19.3 & 33.1 & 665 & 38.2 \\
\hline $95 \% \mathrm{Cl}$ & $16.9-18.9$ & $16.1-22.5$ & $29.4-37.4$ & 477.2 - 893.3 & $34-42.9$ \\
\hline $\mathrm{R}^{2}$ & 0.99 & 0.95 & 0.95 & 0.78 & 0.96 \\
\hline \multicolumn{6}{|c|}{ Hemolysis } \\
\hline $\mathrm{IC}_{50}(\mathrm{nM})$ & 4.9 & 14.3 & 18.4 & 21.3 & 128.8 \\
\hline $95 \% \mathrm{Cl}$ & $3.7-7.2$ & $10.8-21.7$ & $14.3-27.2$ & $14.8-37.0$ & $115.5-152.6$ \\
\hline $\mathrm{R}^{2}$ & 0.96 & 0.89 & 0.96 & 0.98 & 0.70 \\
\hline
\end{tabular}




\section{Supplementary Information for}

\section{A synthetic protein as efficient multitarget regulator against complement over-activation}

Natalia Ruiz-Molina ${ }^{1}$, Juliana Parsons ${ }^{1}$, Madeleine Müller ${ }^{1}$, Sebastian N.W Hoernstein ${ }^{1}$, Lennard L. Bohlender ${ }^{1}$, Steffen Pumple ${ }^{1}$, Peter F. Zipfel ${ }^{5}$, Karsten Häffner ${ }^{6}$, Ralf Reski ${ }^{1,2,3,4}$, Eva L. Decker ${ }^{1 *}$

*Correspondence: Eva L. Decker, eva.decker@biologie.uni-freiburg.de

This PDF file includes:

Figures S1 to S6

Tables S1 to S5 


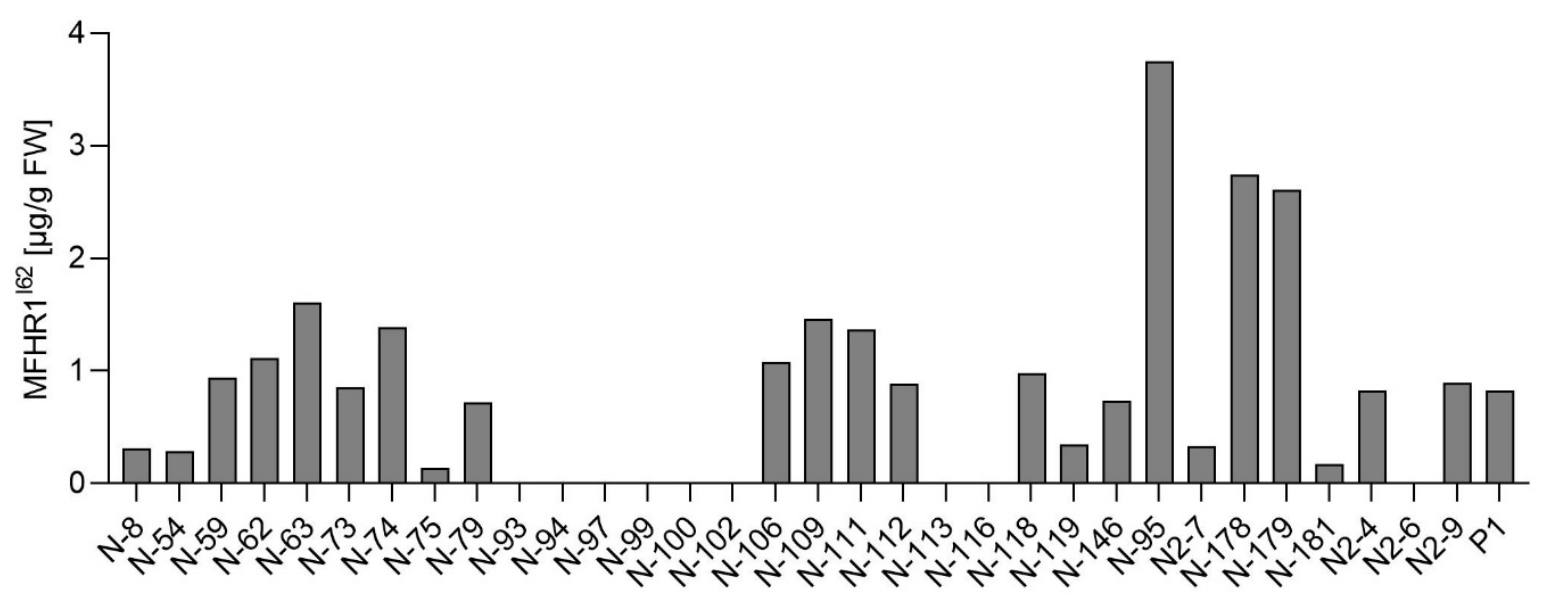

Fig. S1. MFHR1 ${ }^{162}$ productivity. Plants surviving the selection were screened for productivity in suspension cultures in agitated flasks via ELISA. P1 is the MFHR1 ${ }^{\mathrm{V} 62}$ moss producer line, which was included as an internal positive control 
a

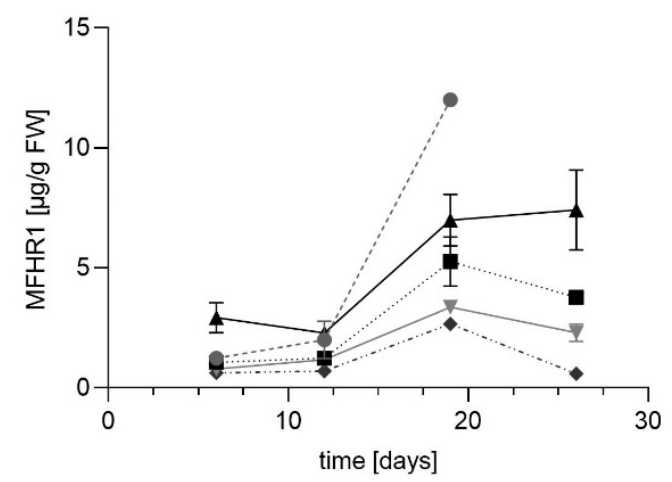

b

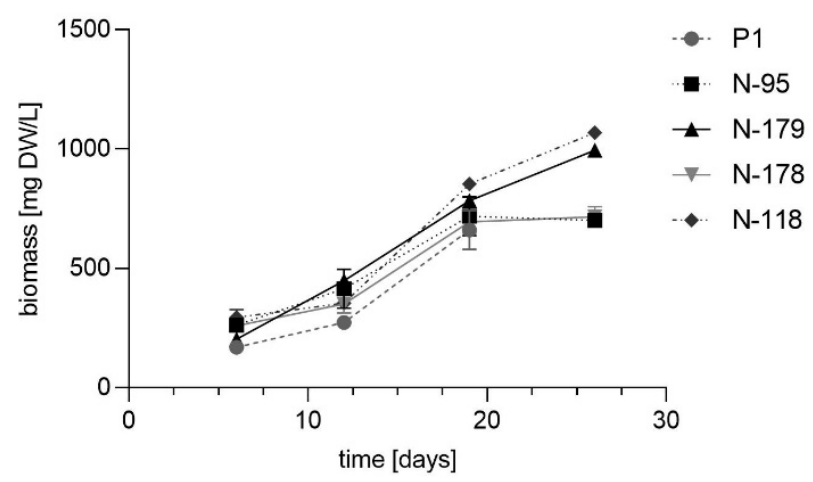

Fig. S2. Kinetics of a) MFHR1 ${ }^{162}$ specific productivity and b) biomass accumulation of 4 of the best lines tested in agitated flasks. 


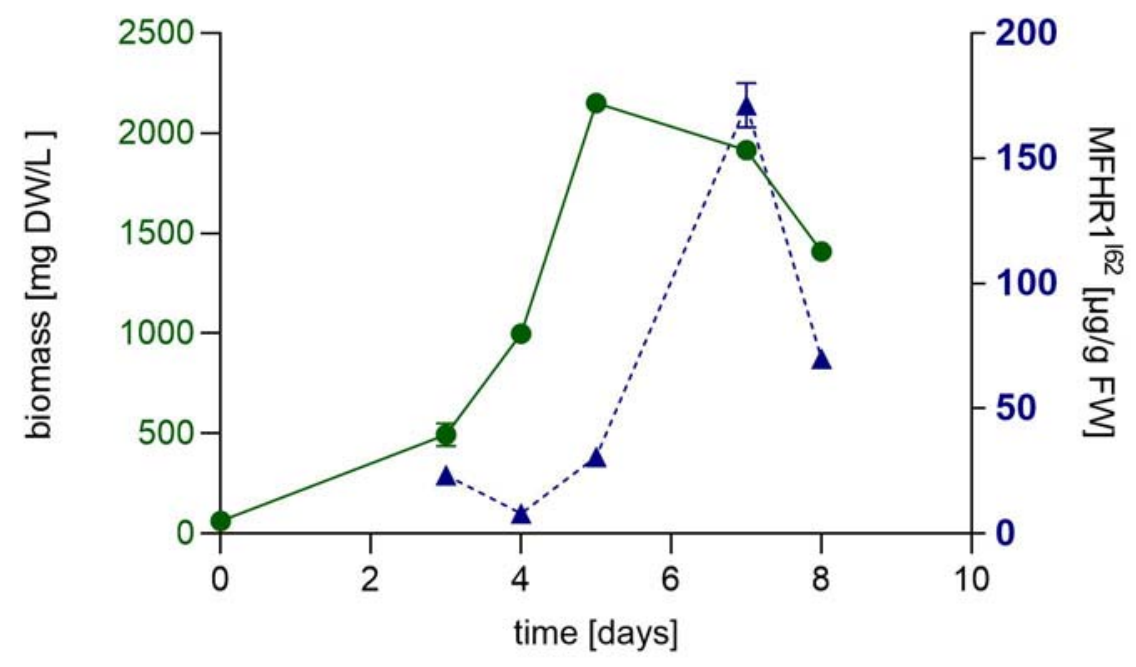

Fig. S3. Kinetics of biomass accumulation and MFHR $1^{162}$ levels of plant $\mathrm{N}-179$ in a $5 \mathrm{~L}$ stirred bioreactor. 
a

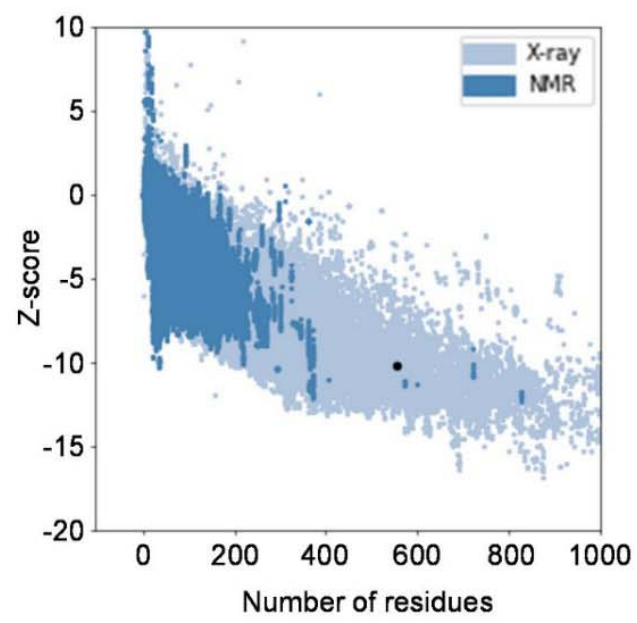

b

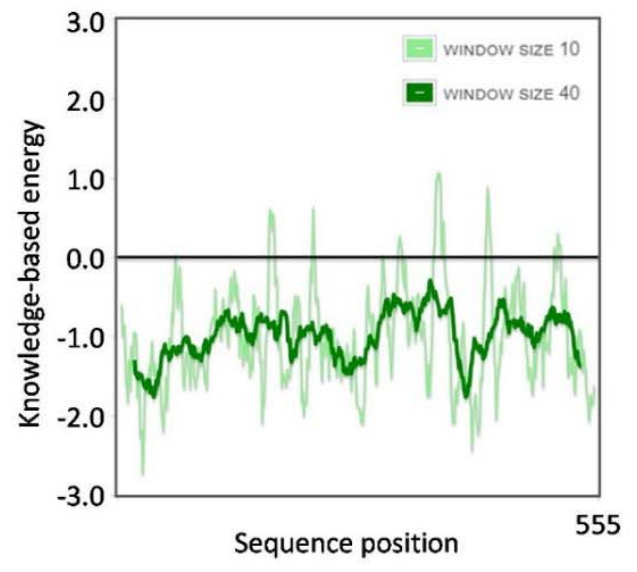

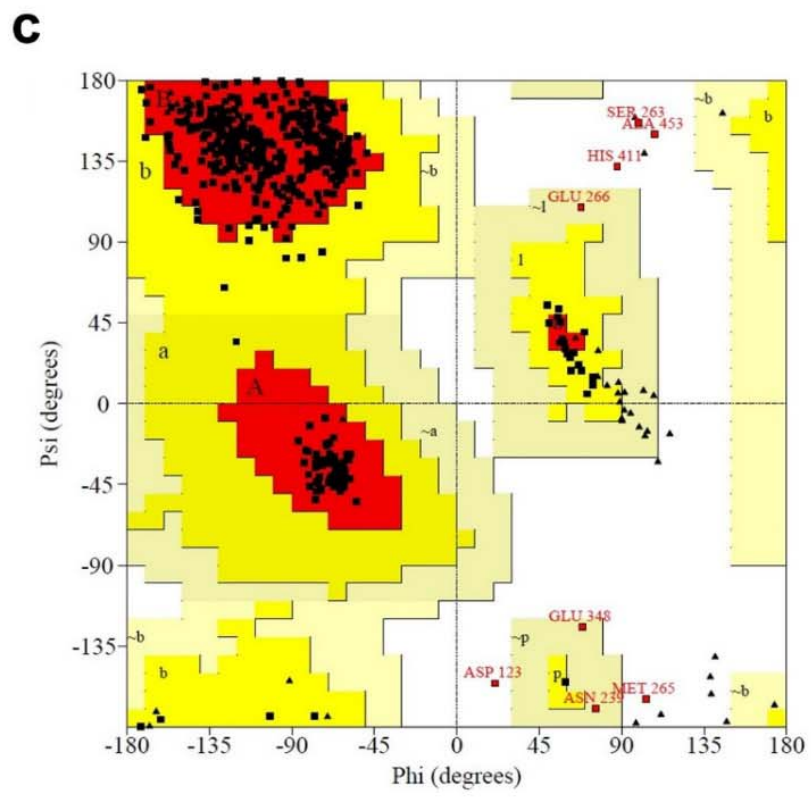

Fig. S4. Assessment of the overall and local quality of the comparative protein structure model. (a) Overall model quality of MFHR13 obtained by ProsaWEB. Z-score: -10.07. (b) Local model quality. Diagram of energy as a function of residues sequence position. Average energy over 40 or 10 amino acid fragments was calculated by ProsaWEB. (c) Ramachandran plot analysis by PROCHECK web-based tool of the model MFHR13. The most favored regions are colored red (labeled A, B, L), allowed regions are colored dark yellow (labeled a, b, I, p), and generously allowed regions are colored in shades of light yellow (labeled $\square \mathbf{a}, \square \mathbf{b}, \square \mathrm{I}, \square \mathrm{p}$ ), while amino acids in disallowed regions are indicated as red squares. The analysis revealed that $97.6,1.3$ and 1.1\% of the residues are located in favored, allowed and outlier regions, respectively. 

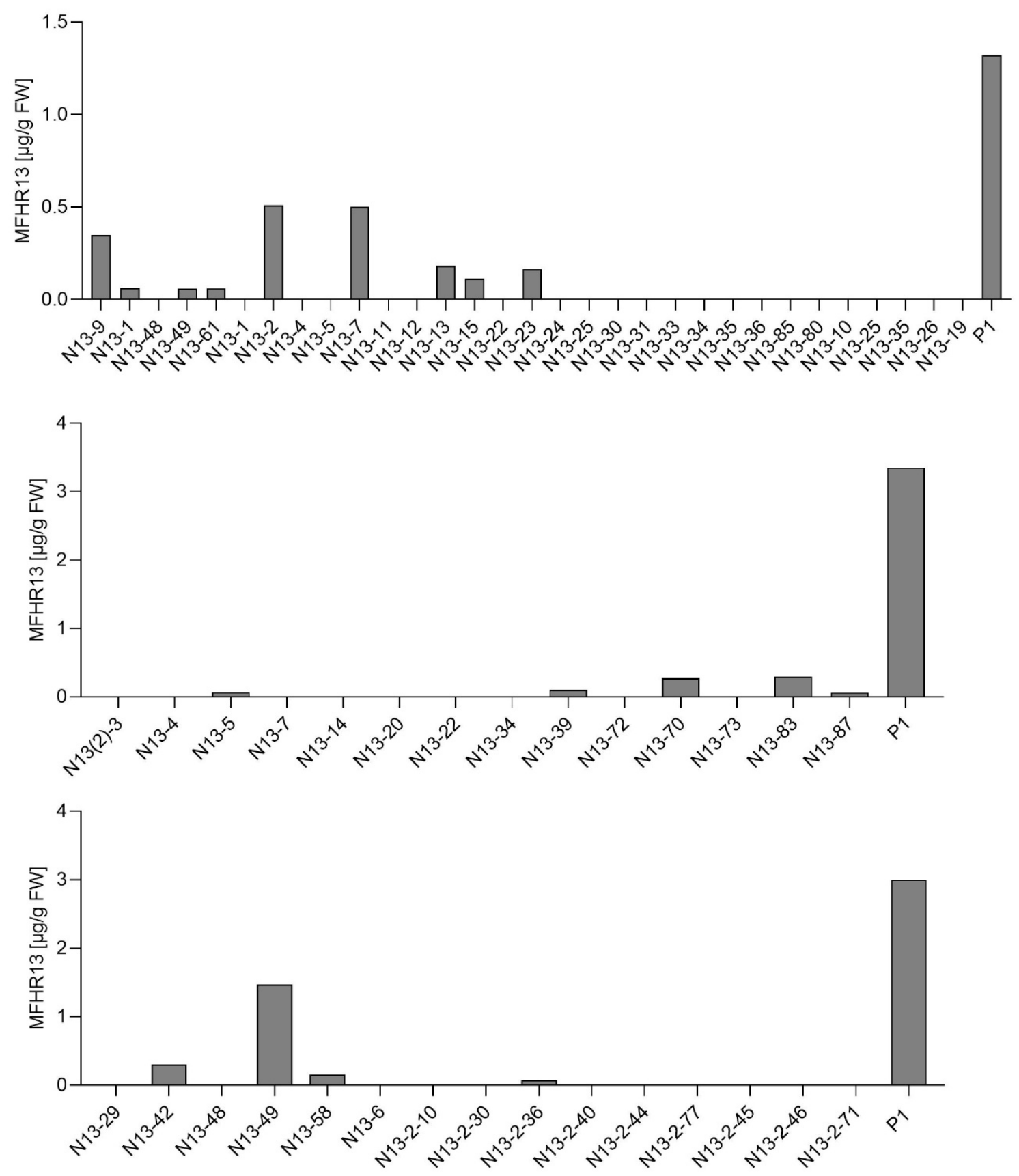

Fig. S5. MFHR13 productivity. All plants surviving the selection were screened for productivity via ELISA in suspension cultures in agitated flasks. P1 is the MFHR ${ }^{\mathrm{V} 62}$ moss producer line, which was included as an internal positive control. 


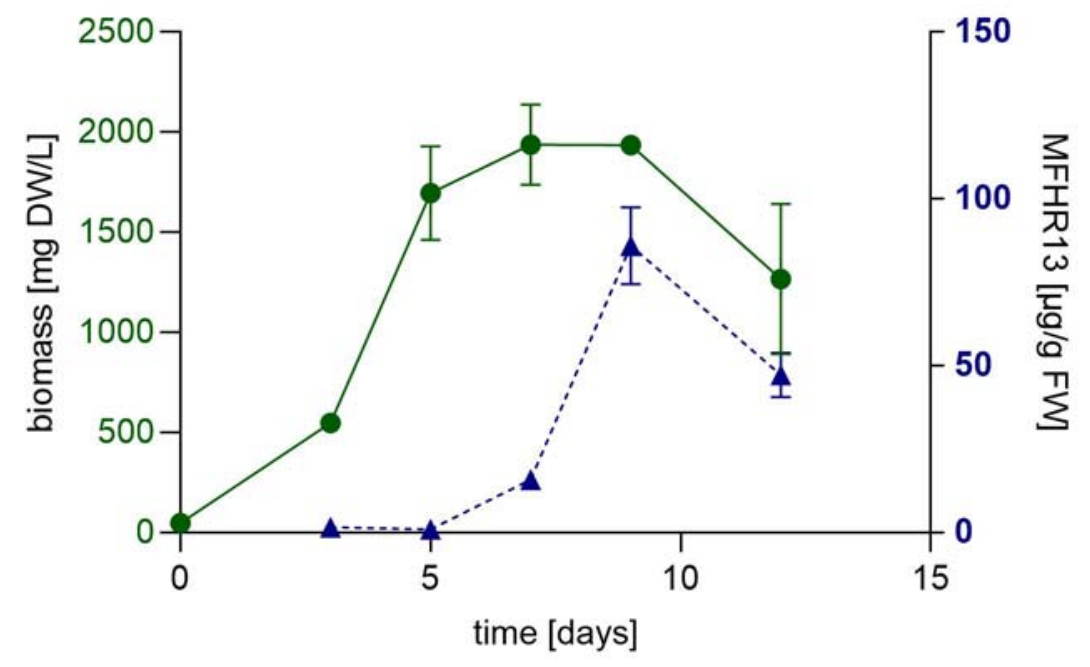

Fig. S6. Kinetics of biomass accumulation and MFHR13 specific productivity of line N13-49 in a $5 \mathrm{~L}$ stirred bioreactor. 


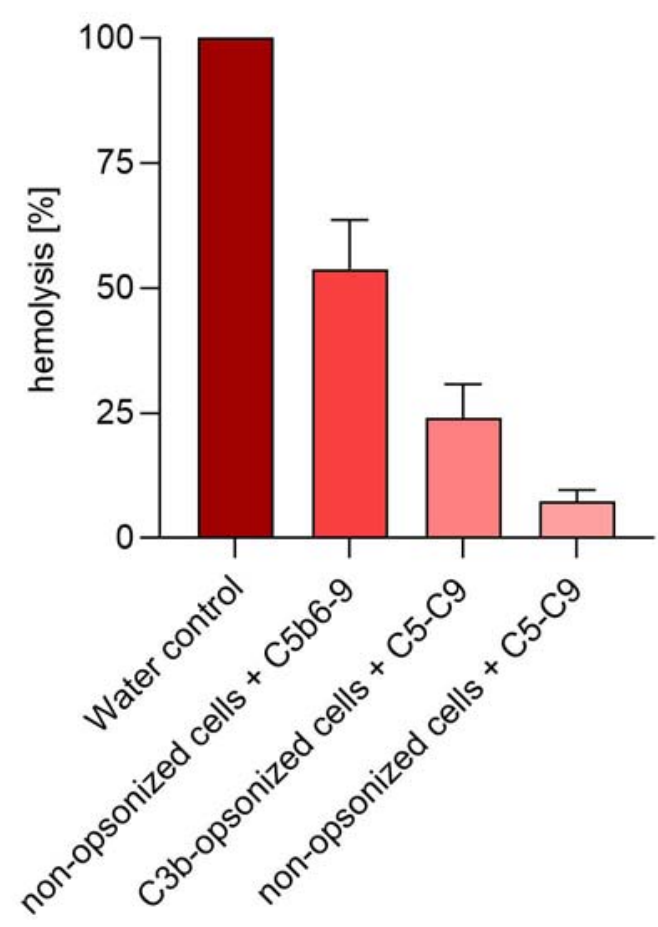

Fig. S7. Comparison of hemolysis achieved by convertase-dependent and convertaseindependent activation of $\mathbf{C 5}$. The extent of hemolysis achieved after activating $\mathrm{C} 5$ in the absence of convertases by using C3b-opsonized sheep erythrocytes exposed to C5-C9 mixture (equivalent to $20 \%$ normal human serum) is weaker than the C5b6-mediated hemolysis in non-opsonized cells. Additionally, a negative control of non-opsonized cells exposed to C5-C9 is included. Cells in water were set to $100 \%$. Data represent mean values \pm SD from 3 independent experiments. 
Table S1. Primers used to create the expression constructs pAct5-MFHR1 ${ }^{162}$ and pAct5-MFHR13, by directed mutagenesis and Gibson assembly respectively. Mismatch for codon exchange is shown in red and the overhangs (overlapping regions for Gibson assembly) in lowercase.

\begin{tabular}{ll} 
MFHR1_I62_fwd & TCTTGGAAATATAATAATGGTATGCAG \\
\hline MFHR1_I62_rev & GATCTATATCCAGGGCGG
\end{tabular}

SCR13_overlapSCR4_fwd gatggcgtccgttgccttcatgtGTGGCAATAGATAAACTTAAGAAG

SCR13_overlapSCR19_rev tgtcaataggtggagggggcccacaTAATTGTATTTGTGCCATTG

SCR4_overlapSCR13_rev cttcttaagtttatctattgccacACATGAAGGCAACGGACGC

SCR19_overlapSCR13_fwd ctgctcaatggcacaaatacaattaTGTGGGCCCCCTCCACC 
Table S2: Estimated $I C_{50}$ values for $\mathrm{C} 3 \mathrm{~b}$ and $\mathrm{C} 5$ binding of MFHR1 $1^{162}$ and MFHR1 ${ }^{\mathrm{V} 62}$ by fitting the data shown in figure 2a,b with 4PL nonlinear regression model. $\mathrm{Cl}$ : Confidence Interval, $\mathrm{R}^{2}$ : Goodness of Fit. Comparison of fits was carried out using the extra sum-of-squares $\mathrm{F}$ test $\mathrm{C} 3 \mathrm{~b}$ binding: $P=0.0437, F(D F n, D f d)=4,338(1,40)$ C5 binding: $P=0.9328, F(D F n, D f d)=0.007207$ $(1,40)$. $D F=$ degrees of freedom

\begin{tabular}{lll}
\hline & MFHR1 $^{162}$ & MFHR1 $^{\text {V62 }}$ \\
\hline C3b binding & \\
\hline $\mathrm{IC}_{50}(\mathrm{nM})$ & 4.70 & 6.32 \\
\hline $95 \% \mathrm{Cl}$ & $3.82-5.80$ & $5.88-6.80$ \\
\hline $\mathrm{R}^{2}$ & 0.99 & 0.99 \\
\hline $\mathrm{C5}^{\mathrm{b} \text { binding }}$ & & \\
\hline $\mathrm{IC} \mathrm{C}_{50}(\mathrm{nM})$ & 26.83 & 26.83 \\
\hline $95 \% \mathrm{Cl}$ & $18.15-56.97$ & $18.15-56.97$ \\
\hline $\mathrm{R}^{2}$ & 0.99 & 0.99 \\
\hline
\end{tabular}


Table S3: Estimated $\mathrm{IC}_{50}$ values for heparin binding of MFHR13 and MFHR1 variants fitting the data shown in figure $5 \mathrm{a}$ with $4 \mathrm{PL}$ nonlinear regression model. Cl: Confidence Interval, $\mathrm{R}^{2}$ : Goodness of Fit. Comparison of fits was carried out using the extra sum-of-squares $\mathrm{F}$ test. $\mathrm{P}<$ $0.0001, F(D F n, D f d)=29.76(2,94)$. MFHR13 vs MFHR1 $1^{162} P<0.0001, F(D F n, D f d)=23.42(1,66)$. MFHR13 vs MFHR1 ${ }^{\mathrm{V} 62} \mathrm{P}<0.0001, \mathrm{~F}(\mathrm{DFn}, \mathrm{Dfd})=42.53(1,67) . \mathrm{DF}=$ degrees of freedom,

\begin{tabular}{llll}
\hline $\begin{array}{l}\text { Heparin } \\
\text { binding }\end{array}$ & MFHR13 & MFHR1 $^{162}$ & MFHR1 $^{\text {V62 }}$ \\
\hline $\mathrm{IC}_{50}(\mathrm{nM})$ & 0.24 & 0.50 & 0.76 \\
\hline $95 \% \mathrm{Cl}$ & $0.20-0.28$ & $0.4-0.65$ & $0.58-1.17$ \\
\hline $\mathrm{R}^{2}$ & 0.98 & 0.98 & 0.98 \\
\hline
\end{tabular}


Table S4. Estimated $I C_{50}$ values for $\mathrm{C} 3 \mathrm{~b}$ and $\mathrm{C} 5$ binding of MFHR $1^{162}$ and MFHR13 by fitting the data shown in figure $6 \mathrm{a}$ and $7 \mathrm{a}$ with $4 \mathrm{PL}$ nonlinear regression model. $\mathrm{Cl}$ : Confidence Interval, $\mathrm{R}^{2}$ : Goodness of Fit. Comparison of fits was carried out using the extra sum-of-squares $\mathrm{F}$ test. C3b binding $P=0.8426 F(D F n, D f d)=0.0397(1,71)$. C5 binding $P=0.2565 F(D F n, D f d)=1.309(1,69)$. $\mathrm{DF}=$ degrees of freedom

\begin{tabular}{lll}
\hline C3b binding & MFHR13 & MFHR1 \\
\hline $\mathrm{IC}_{50}(\mathrm{nM})$ & 16.05 & 16.05 \\
\hline $95 \% \mathrm{Cl}$ & $8.79-635.1$ & $8.79-635.1$ \\
\hline $\mathrm{R}^{2}$ & 0.93 & 0.91 \\
\hline $\mathbf{C 5}$ binding & & \\
\hline $\mathrm{IC}$ & & \\
\hline $95 \% \mathrm{nM})$ & 52.5 & 52.5 \\
\hline $\mathbf{R}^{2}$ & Not calculated & Not calculated \\
\hline
\end{tabular}


Table S5. $\mathrm{IC}_{50}$ calculated by $4 \mathrm{PL}$ nonlinear regression model for decay acceleration activity (DAA), fitting the data shown in figure $6 \mathrm{~d}$. Cl: Confidence Interval, $\mathrm{R}^{2}$ : Goodness of Fit. Comparison of fits was carried out using the extra sum-of-squares $F$ test. MFHR13 vs MFHR ${ }^{162} \mathrm{P}<0.0001 \mathrm{DFn}, \mathrm{DFd}=$ $196.6(1,28)$. MFHR13 vs MFHR ${ }^{\mathrm{V} 2} \mathrm{P}<0.0001 \mathrm{DFn}, \mathrm{DFd}=131.5(1,31) . \quad \mathrm{MFHR} 13$ vs $\mathrm{hFH}$ $\mathrm{P}=0.2022 \mathrm{~F}$ (DFn, DFd) $1.7(1,30)$. DF= degrees of freedom

\begin{tabular}{lllll}
\hline & MFHR13 & MFHR1 $^{162}$ & MFHR1 $^{\mathrm{V62}}$ & hFH \\
\hline $\mathrm{IC}_{50}(\mathrm{nM})$ & 2.70 & 7.8 & 9.45 & 3.84 \\
\hline $95 \% \mathrm{Cl}$ & $2.2-3.3$ & $6.2-9.99$ & $7.7-11.7$ & $2.95-5.07$ \\
\hline $\mathrm{R}^{2}$ & 0.99 & 0.96 & 0.95 & 0.96 \\
\hline
\end{tabular}

